\title{
Manipulating Stress Receptor Signaling to Enhance Immunosuppression and Prolong Survival of Vascularized Composite Tissue
}

Minhyung Kim ( $\square$ Minhyung.Kim@RoswellPark.org )

Roswell Park Comprehensive Cancer Center

Daniel Fisher

Roswell Park Cancer Institute

Paul Bogner

Roswell Park Cancer Institute

Umesh Sharma

University at Buffalo

Joseph Skitzki

Roswell Park Cancer Institute

Elizabeth Repasky

Roswell Park Comprehensive Cancer Center

Article

Keywords: vascularized composite tissue, immunosuppression, adrenergic receptors

Posted Date: September 20th, 2021

DOI: https://doi.org/10.21203/rs.3.rs-871136/v1

License: (1) This work is licensed under a Creative Commons Attribution 4.0 International License.

Read Full License 
1 Title:

\section{Manipulating Stress Receptor Signaling to Enhance Immunosuppression and Prolong Survival of Vascularized Composite Tissue}

Authors: Minhyung Kim ${ }^{1,2^{*}}$, Daniel T. Fisher ${ }^{1,2}$, Paul N. Bogner ${ }^{3}$, Umesh Sharma ${ }^{4}$, Joseph J.

Skitzki ${ }^{1,2}$, and Elizabeth A. Repasky ${ }^{2 *}$

\section{Affiliations:}

${ }^{1}$ Department of Surgical Oncology, Roswell Park Comprehensive Cancer Center, Buffalo, New York, USA.

${ }^{2}$ Department of Immunology, Roswell Park Comprehensive Cancer Center, Buffalo, New York, USA.

${ }^{3}$ Department of Pathology, Roswell Park Comprehensive Cancer Center, Buffalo, New York, USA.

${ }^{4}$ Department of Medicine, Division of Cardiology, University at Buffalo, Buffalo, New York, USA.

*Corresponding authors: Elizabeth A. Repasky, Department of Immunology, Roswell Park Comprehensive Cancer Center, Elm \& Carlton streets, Buffalo, NY 14263, USA. Tel: +1 716845 3133; Fax: +17168458552 .

E-mail address: Elizabeth.Repasky@RoswellPark.org

And

Minhyung Kim, Department of Surgical Oncology, Roswell Park Comprehensive Cancer Center, Elm \& Carlton streets, Buffalo, NY 14263, USA. Tel: +1 716845 2974; Fax: +1 7168452320.

E-mail address: Minhyung.Kim@RoswellPark.org

One Sentence Summary: Enhancing immunosuppression by adrenergic receptor manipulation using a $\beta_{2}$-agonist enhances VCA graft survival without increasing toxicity. 
28 Abstract: Vascularized composite tissue allotransplantation (VCA) can replace severely damaged body parts but the unavoidable toxicity of high doses of immunosuppressive drugs, such as tacrolimus, required results in significant morbidity. Here we tested whether we could suppress immune activity in a mouse model of VCA by mimicking the natural immune suppression generated by nervous system-induced signaling of adrenergic receptors (AR) by using a safe and well-studied $\beta$-AR agonist (terbutaline). Using wild-type and $\beta_{2}$-AR-knockout (KO) mice, we found that increased $\beta_{2}$-AR signaling results in delayed rejection in VCA recipients, even with subtherapeutic doses of tacrolimus, and this was associated with changes in immune contexture, expression of pro-inflammatory cytokines and chemokines, and function of endothelial adhesion molecules. We propose that $\beta$-AR agonists can be used safely to mimic the natural suppression of immune responses generated by adrenergic stress signaling and thereby reduce the dose needed of other more toxic immunosuppressive drugs. 


\section{Introduction}

Remarkable improvements in on-site emergency care have led to increased survival of patients with previously fatal traumatic injuries resulting from accidents, gun-shots or explosions in both civilian and military settings ${ }^{1-3}$. However, these surviving patients must endure life-long difficulties associated with the loss of legs, arms, hands or other functional units (including even faces) with a significant decline in quality of life. This difficult situation has generated interest in testing new transplant protocols using body parts from cadaveric donors in a procedure known as vascularized composite tissue allotransplantation (VCA). With more than 90 patients receiving VCA over the past decade, this novel transplantation is raising hope for patients with devastating deformities and complex tissue defects ${ }^{4-7}$. In large part, these successes have been achieved both by improved microsurgical techniques (e.g., anastomoses of vessels and nerves) and the use of large doses of potent pharmacological agents to induce immunosuppression, including cyclosporine $\mathrm{A}$, tacrolimus and mycophenolic acid ${ }^{8-11}$. However, despite the excitement surrounding VCA, significant challenges prevent its widespread acceptance and use. First and foremost is that tissues and organs recovered from cadaveric donors are a scare resource with few instances of HLA-match with the recipient ${ }^{12}$. As a result, very heavy doses of immunosuppressive medications are required, exposing the patient to opportunistic infections, hyperglycemia, hepatotoxicity, nephrotoxicity, cancer and reproductive toxicity ${ }^{13}$. Additionally, in vivo and in vitro studies suggest that the immunosuppressants cyclosporine and tacrolimus can promote carcinogenesis and cancer progression through production of transforming growth factor- $\beta$, increasing tumor angiogenesis and metastasis ${ }^{14,15}$. Adverse reactions and toxicity often necessitate reduction, and even complete withdrawal, of immunosuppressive drugs leading to a tragic graft rejection and loss. As an example of this scenario, a patient who received the first face transplantation in 2005 suffered from two different types of cancer as a consequence of potent 
immunosuppression and subsequently lost her lips due to graft rejection ${ }^{16}$. Although, VCA can provide significant improvement in quality of life, far too many of these patients experience either graft rejection or increased risk of additional health problems, including cancer, from the chronic use of high dose immunosuppressive drugs ${ }^{13}$. This has led to significant ethical concerns about using this type of transplant in patients when it is not medically "life-saving" unlike the situation for patients requiring solid organ transplants such as liver or heart, which is medically required to save their lives. Moreover, in the latter case, these is often a better possibility to achieve a closer donor HLA match. So, it is clear that there is a serious and unmet medical need for new strategies to improve graft survival after VCA and lessen the risk of lifethreatening morbidities from toxic immunosuppressive drugs.

The nervous and immune systems have been found to interact closely in host defense and stress responses ${ }^{17}$. Although the relationship of the hypothalamus-pituitary-adrenal (HPA) axis and cortisol has been well studied ${ }^{18,19}$, the natural role of the sympathetic nervous system in regulating immune responses is not fully understood ${ }^{20,21}$. Sympathetic and parasympathetic nerves are found innervating immune organs and near immune cells throughout the body. Extensive research now shows that neurotransmitter interactions between norepinephrine (NE) and $\beta$-adrenergic receptors (AR) regulate the immune system and that dysregulation of neuroimmune signaling pathways contributes to the pathogenesis of immune disorders ${ }^{22-24}$.

Recently, we have shown that pharmacologic blockade of the $\beta$-AR with the common pan- $\beta$-blocker propranolol reduces tumor growth rates by interfering with the suppressive activity of adrenergic stress on adaptive immune responses. Specifically, we found that blocking $\beta$-AR with propranolol increased glucose uptake and glycolysis needed for metabolic reprogramming during $\mathrm{T}$ cell activation and anti-tumor immunity ${ }^{25-28}$. We also found that $\beta_{2}$ $\mathrm{AR}$ has an important role for immune modulation of $\mathrm{T}$ cells and myeloid-derived suppressor cells $(\mathrm{MDSC})^{29}$. The strong, naturally occurring immunosuppressive potential of $\beta$-AR 
signaling is consistent with our observations that adrenergic stress or addition of $\beta$-AR agonists can suppress graft versus host disease (GVHD) following bone marrow transplantation $(\mathrm{BMT})^{29-31}$

These data led us to investigate whether targeting the natural ability of $\beta$-AR to regulate immunity in response to adrenergic stress signaling could be used to more safely promote an immunosuppressive environment in transplanted grafts following VCA, thus allowing a reduction of the dose of the more toxic immunosuppressant drug tacrolimus. Here, we investigated the impact of targeting $\beta_{2}$-AR using the $\beta_{2}$-blocker terbutaline, on graft rejection rate and immune contexture using wild-type and $\beta_{2}$-AR-knockout $(\mathrm{KO})$ mice. We found that increased $\beta_{2}-\mathrm{AR}$ activation results in delayed rejection responses in VCA recipients without detectable toxicity and this occurred through mechanisms involving pro-inflammatory cytokines and chemokine suppression as well as inhibition of endothelial adhesion molecules. More importantly, we were able to extend graft survival using a subtherapeutic dose of tacrolimus combined with $\beta_{2}$-AR agonist. Together, these data reveal an immediately feasible strategy which can be tested in patients receiving VCA or other types of allotransplants.

\section{Results}

\section{Safety and cross-reactivity with tacrolimus of selective $\beta_{2}$-AR agonist}

Our previous work has established a reliable and consistent platform using a pre-clinical murine model of hind limb $\mathrm{VCA}^{32}$ to investigate novel therapies to prolong transplant survival The transplanted graft consisted of skin, fat, muscle, bone and blood vessels (Supplementary Fig. 1a), a complex combination of tissues similar to those which are often used in VCA.

While we know from the literature and its clinical safety profile that terbutaline is considered to be a safe drug, we wanted to be sure that there were no cardiac physiology problems generated by this $\beta_{2}$-AR agonist alone, or in combination with the drug tacrolimus, 
a drug that causes significant immunosuppression and commonly used in the transplant setting ${ }^{13,33}$. We assessed blood pressure (BP) and heart rate (HR) with a non-invasive tail cuff system $^{34}$. Normal mice were acclimated to the device for 10 days prior to collecting readings. No statistical difference was detected in systolic/diastolic BP or HR between mice treated daily with $\beta_{2}$-AR agonist or vehicle over a course of 11 days (Supplementary Fig. 1b). We also measured plasma levels of tacrolimus in the mice treated with two different doses; full dose

134 (fTac, i.e., a dose known to generally maintain allografts long term ${ }^{32}$ ), and half dose (hTac, i.e., a dose that only delays graft rejection) were measured. As expected, significantly higher drug concentrations were measured in the fTac injected group compared to the hTac group, but there tacrolimus alone and mice treated with tacrolimus and $\beta_{2}-\mathrm{AR}$ agonist combination (Supplementary Fig. 1c). In addition, no changes of body weight and physical appearance were 
day 7, which was further improved by the addition of subtherapeutic dose of tacrolimus (hTac), with some grafts surviving with grade 2 rejection at day 10 (Fig. 1b). Although no evidence of gross rejection was observed at day 5 , various histologic rejection grades were detected with H\&E. $\beta_{2}$-agonist treatments delayed rejection responses with/without subtherapeutic dose of tacrolimus compared to the vehicle injected group (Fig. 1c).

To determine whether infiltrating cells originated from the donor or the recipient, we took advantage of differential CD45 isoform usage of C57BL/6 recipient (CD45.1) and BALB/c donor (CD45.2) mice. By day 7 post-VCA, over $90 \%$ of leukocytes within grafts (Supplementary Fig. 2a) and peripheral blood (Supplementary Fig. 2b) were from recipients. Reduced lymphocyte infiltration into the graft at an early phase of rejection would be expected to correlate with the observed enhanced graft survival. While moderate perivascular inflammation was detected at day 5 in the $\beta_{2}$-agonist treated group (pathology grade 2), epithelial apoptosis and dyskeratosis were distinct in the vehicle treated group (pathology grade 3) (Fig. 2a, b and Supplementary Fig. 3a, b). Infiltrating lymphocytes $\left(\mathrm{CD} 4^{+} \mathrm{T}, \mathrm{CD} 8^{+} \mathrm{T}\right.$, and Foxp $3^{+}$cells) were concentrated in the donor, but not recipient tissue, in both vehicle (Fig. 2a) and $\beta_{2}$-agonist (Fig. 2b) treated mice, however, fewer lymphocytes infiltrated the grafts in the $\beta_{2}$-agonist group (Fig. 2c). Although significantly less T cell infiltration was detected in $\beta_{2}$ agonist treated grafts, compositions of $\mathrm{CD} 4^{+} / \mathrm{CD} 8^{+}$central memory $(\mathrm{CM})$ and effector memory (EM) T cell populations did not show a statistical difference by flow cytometry 5 days after VCA in the grafts (Fig. 2d). By day 7, the histological delineation between epidermis and dermis was lost and tissue rejection was nearly complete in the vehicle (Supplementary Fig. 3c) compared to the $\beta_{2}$-agonist group (Supplementary Fig. $3 \mathrm{~d}$ ) and infiltrated CD4 ${ }^{+} \mathrm{T}, \mathrm{CD} 8^{+} \mathrm{T}$ and Foxp $3^{+}$cells found in vehicle controls were declining resulting in no statistical difference with the $\beta_{2}$-agonist treated group (Supplementary Fig. 3e). The majority of T cells in the grafts 7 days after VCA were EM cells in both groups, and these values were higher than healthy 
donor (pre-transplanted grafts) control specimens (Supplementary Fig. 3f).

To test whether we could use a $\beta$-AR agonist to mimic natural NE and $\beta$-AR interactions and reduce the dose of tacrolimus needed for immunosuppression, we tested tacrolimus at half dose (hTac) in combination with either vehicle or $\beta_{2}$-agonist. Grade 4 graft rejection was observed 10 days after VCA in the hTac + vehicle group, while the hTac $+\beta_{2}$ group showed mainly only Grade 2 with partial Grade 3 rejection with intact skin histology (Fig. 2e). Abundant $\mathrm{CD}^{+} \mathrm{T}$ and $\mathrm{CD}^{+} \mathrm{T}$ cell infiltration was present 7 days after VCA in the hTac+vehicle group, and then the values dropped significantly 3 days later. $\beta_{2}$-agonist treatments significantly decreased the number of infiltrating $\mathrm{CD}^{+} \mathrm{T}$ and $\mathrm{CD} 8^{+} \mathrm{T}$ cells at day 7 compared to the hTac+vehicle group, but more $\mathrm{CD}^{+} \mathrm{T}$ cell infiltration was found in the $\beta_{2}-$ agonist treated group than the vehicle injected group at day 10 representing remnant immune responses in the graft (Fig. 2f). There was no statistical difference in the proportion of CM and EM T cell populations in grafts 7 days after VCA between two groups using hTac (Fig. 2g).

\section{Changes in memory $T$ and $T h 1$ cells with a $\beta_{2}-A R$ agonist treatment in recipients}

In contrast to observations within grafts by flow cytometry (Fig. $2 \mathrm{~d}, \mathrm{~g}$ ), $\beta_{2}$-AR agonist treatment significantly decreased the representation of $\mathrm{CD}^{+}$and $\mathrm{CD} 8^{+}$memory $(\mathrm{CM}$ and $\mathrm{EM})$ $\mathrm{T}$ cell populations in the recipient's systemic blood compartment (spleen) at day 5 (i.e., before the emergence of signs of rejection; Fig. 3a), however, by day 7 (i.e., once gross signs of rejection are apparent) these differences were lost (Fig. 3b). This finding was more pronounced in the EM T cell population in mice treated with hTac. Additional decreases in the $\mathrm{CD}^{+} \mathrm{T}$ and $\mathrm{CD}^{+} \mathrm{T}$ EM populations were found with $\beta_{2}$-agonist treatment at day 7 (Fig. 3c), and these differences are lost by day 10 (Fig. 3d). $\beta_{2}$-agonist decreased the compositions of Th1 population significantly compared to the vehicle group at day 5 and 7 without tacrolimus (Fig. 3e) and at day 7 and 10 with hTac (Fig. 3f). Interestingly, higher Treg (CD4 ${ }^{+} \mathrm{CD} 25^{+} \mathrm{Foxp}^{+}$) levels in the graft (Fig. 2c) and the body (spleen; Fig. 3e) did not predict a better prognosis for 
transplanted grafts. There were more Foxp $3^{+}$cell infiltration in grafts and a greater Treg population systemically along with more infiltrated T cells in grafts. The Treg population was directly proportional to the severity of $\mathrm{T}$ cell infiltration in grafts after VCA. Accordingly, a smaller Treg population was found in grafts and the recipients treated with fTac (Supplementary Fig. 4). Thus, Treg populations, which are thought to have immunosuppressive effects, may have increased as a consequence of a fulminant immune response to the highly antigenic VCA.

\section{Analyses of inflammatory cytokine levels after $\beta_{2}-A R$ modulation in recipients}

Luminex analyses were used to determine if differences in the expression of inflammatory cytokines are associated with graft rejection after VCA followed by vehicle or $\beta_{2}$-agonist injections. Systemic cytokines in recipient's plasma were measured. Significantly decreased IFN- $\gamma$, IL-6, and TNF- $\alpha$ levels with increased IL-13 levels were found in the $\beta_{2}$ agonist group compared to the vehicle group 5 days after VCA. The elevated cytokines (IFN$\gamma$, IL-6, IL-18, and TNF- $\alpha$ ) decreased 2 days later was indicative of their likely role in graft rejection responses before phenotypic rejection was noted (Fig. 3g).

\section{Augmentations of subtherapeutic immunosuppression using tacrolimus in combination}

\section{with $\beta_{2}-A R$ agonist}

$\beta_{2}$-AR agonist was evaluated for its effects on the survival of grafts after cessation of immunosuppression. Recipients were given with fTac every day for 14 days, and then tacrolimus injection was stopped, and vehicle or $\beta_{2}$-agonist injections were initiated and continued until grafts showed rejection (Fig. 4a). Distinct effects of $\beta_{2}$-agonist treatment on suppression of memory $\mathrm{T}$ cell populations were not detected in the blood (Fig. 4b), and there was no survival benefit of grafts given $\beta_{2}$-agonist following cessation of tacrolimus (Fig. 4c). However, with a scenario using hTac with either vehicle or $\beta_{2}$-agonist (Fig. $4 \mathrm{~d}$ ), the dose of tacrolimus was reduced by half 14 days after a full dose of tacrolimus daily treatment (fTac to 
hTac). Even though no statistical difference on $\mathrm{CD}^{+}$and $\mathrm{CD} 8^{+}$memory $\mathrm{T}$ cell populations was detected between two groups in the blood (Fig. 4e), there was a significant graft survival benefit in the $\beta_{2}$-agonist group compared to the vehicle group (Fig. 4f).

\section{Effects of $\beta_{2}-A R$ modulation in donor tissue}

A well-studied adrenergic receptor knockout (AR KO) mouse strain as donors and recipients were used to investigate the specific role of $\beta_{2}$-AR in the treatments of either donor or recipient ${ }^{29}$. Grafts were harvested from BALB/c AR KO mice as donors, and transplanted into C57BL/6 wild-type (WT) recipients (Fig. 5a-d). Although the graft showed less severe gross rejection as grade 1 with $\beta_{2}$-agonist compared to the vehicle injection (Fig. 5a), no statistical difference was found in the compositions of $\mathrm{CD}^{+}$and $\mathrm{CD}^{+}$memory $\mathrm{T}$ cell populations at day 5 in the spleen (Fig. 5b). However, the composition of $\mathrm{CD}^{+}$and $\mathrm{CD} 8^{+} \mathrm{EM}$ T cell populations were significantly lower in the $\beta_{2}$-agonist group than the vehicle group at day 7 (Fig. 5c), and significantly less Th1 and Treg were detected with $\beta_{2}$-agonist compared to vehicle at day 5 (Fig. 5d). In parallel, WT grafts were transplanted to C57BL/6 AR KO recipients with either vehicle or $\beta_{2}$-agonist injections (Fig. 5e-h). Significant decreases in CD4 ${ }^{+}$ and $\mathrm{CD}^{+}$memory $\mathrm{T}$ cell populations were detected at day 5 (Fig. 5f) and 7 (Fig. $5 \mathrm{~g}$ ) with gross grade 0 rejection in the $\beta_{2}$-agonist treated group compared to the vehicle group (grade 3 ). In addition, $\beta_{2}$-agonist decreased Treg population significantly compared to vehicle injection at day 5 (Fig. 5h). Furthermore, significant decreases in $\mathrm{CD}^{+} \mathrm{T}$ cell and Treg infiltration were detected with $\beta_{2}$-agonist treatment in AR KO recipients bearing the WT grafts $(\mathrm{WT} \rightarrow \mathrm{KO})$ compared to WT recipients bearing AR KO grafts $(\mathrm{KO} \rightarrow \mathrm{WT})$ (Fig. 5i).

\section{Important actions of $\beta_{2}$-AR agonist on donor stromal cells after VCA}

$\beta_{2}$-AR modulation in donors suppresses rejection responses after VCA, so to better determine the responsible populations of cells, bone marrow (BM) and stromal cells of the donor were examined. WT donors were exposed to 8 Gy (gray) irradiation the day before VCA 
to eradicate $\mathrm{BM}$ cells, and then grafts including a femur was transplanted to $\beta_{2}-\mathrm{AR} \mathrm{KO}$ recipients followed by vehicle or $\beta_{2}$-agonist injections. Both groups showed mild xerosis of grafts with intact skin anatomy (Fig. 6a), and distinct effects of $\beta_{2}$-agonist treatment were lost in the $\mathrm{CD}^{+}$and $\mathrm{CD} 8^{+}$memory T cell (Fig. 6b), Th1 and Treg (Fig. 6c) populations 7 days after VCA. However, significantly lower numbers of $\mathrm{CD}^{+}$and $\mathrm{CD}^{+} \mathrm{T}$ cell infiltrations were found in the $\beta_{2}$-agonist treated graft than the vehicle group (Fig. 6d). Further, $\beta_{2}$-AR KO donor was irradiated, and then WT BMT was performed to generate a chimeric model including $\beta_{2}$-AR KO stromal cells and WT BM, and vice versa (Fig. 7a). Grafts composed of $\beta_{2}-\mathrm{AR}$ KO stromal with WT BM $(\mathrm{KO}+\mathrm{WT})$ showed more severe rejection than WT stromal with AR KO BM $(\mathrm{WT}+\mathrm{KO})$ grafts in AR KO recipients (Fig. 7a, b; KO+WT gross grade 2 and histologic grade 3, $\mathrm{WT}+\mathrm{KO}$ gross grade 1 and histologic grade 2). Greater amounts of $\mathrm{CD} 4^{+} \mathrm{T}$ and $\mathrm{CD} 8^{+} \mathrm{T}$ cell infiltration were found in the KO+WT grafts than the WT $+\mathrm{KO}$ grafts (Fig. 7b). Additionally, significant decreases of $\mathrm{CD} 4^{+}$and $\mathrm{CD}^{+}$memory $\mathrm{T}$ cell populations were detected in the spleen of mice bearing $\mathrm{WT}+\mathrm{KO}$ grafts compared to mice bearing $\mathrm{KO}+\mathrm{WT}$ grafts (Fig. 7c) with no significant difference on Th1 and Treg populations between groups (Fig. 7d). It means that $\beta_{2}$ AR signals in donor's stromal cells have critical roles on recipient's T cell trafficking.

Inhibition of endothelial adhesion molecules and $T$ cell trafficking chemokines with $\beta_{2}$ -

\section{AR agonist}

Leukocyte extravasation is one of the essential and first steps during the initiation of cell-mediated rejection and ICAM-1/2 and VCAM-1 are the endothelial adhesion molecules that mediate firm adhesion just prior to cell extravasation ${ }^{36}$. To investigate changes of endothelial adhesion molecules in donor's vessels after $\beta_{2}$-agonist treatment, WT donor's grafts in WT recipients were stained 5 days after VCA. $\beta_{2}$-agonist suppressed ICAM-1 and VCAM1 expression in graft vessels compared to vehicle, while the expression of ICAM-2 was increased in the $\beta_{2}$-agonist treated group (Fig. 8a) by immunofluorescence. Also, recipient's 
plasma levels of the relevant $\mathrm{T}$ cell trafficking chemokines CXCL-1, CXCL-10, CCL2, CCL3,

CCL4, CCL5, CCL7 and CCL11 increased significantly at day 5, and resolving by day 7. Under pro-inflammatory chemokines that regulates leukocytes trafficking ${ }^{37}$ were decreased significantly compared to the vehicle injection (Fig. 8b).

\section{Effects of donor preconditioning prior to VCA with $\beta_{2}-A R$ agonist}

$\beta_{2}$-agonist treatment before VCA was examined as a pre-conditioning regimen as

$\mathrm{BALB} / \mathrm{c}$ WT mice were given $\beta_{2}$-agonist for 2 weeks prior to VCA (Pre-VCA) and compared to the previous experiments injecting $\beta_{2}$-agonist after VCA (Post-VCA) (Supplementary Fig. 5a). Although similar gross and histologic rejection grades were detected in the Pre-VCA group (grades 1 and 3 respectively) compared to the Post-VCA group (grades 0 and 3 respectively) 7 days after surgery, the immunosuppressive effects on memory $\mathrm{T}$ cell populations in recipients were lost in the setting of Pre-VCA (Supplementary Fig. 5b). But, suppression of the Th1 population and $\mathrm{CD}^{+} \mathrm{T}$ cell trafficking in Pre-VCA were comparable to Post-VCA (Supplementary Fig. 5c, d).

\section{Discussion}

Here, we tested a strategy that mimics the natural ability of nerves and adrenergic stress signaling to suppress $\mathrm{T}$ cell mediated immune responses to prolong survival of a complex tissue allograft. Importantly, we found that we could reduce the dose of a standard immunosuppressant drug tacrolimus to half by supplementing it with a $\beta_{2}$-AR agonist, while obtaining significant immune modulatory effects favoring graft survival. Selective $\beta_{2}$-AR targeting drugs have been safely and extensively used for decades for other indications, particularly for cardiovascular and pulmonary manipulation ${ }^{38}$. Furthermore, at the dose of terbutaline that we used here to prolong graft survival, no changes in $\mathrm{HR}$ and $\mathrm{BP}$ were observed 
with daily use, and no drug interaction with tacrolimus was found, thus supporting the safety of this approach. VCA composes of multiple tissues with different immunogenic and functional properties, including skin, muscles, bones and nerves from cadavers. Also, these cadaveric donors have little chance to match HLA types with the recipients. As a result, these donor tissues are highly antigenic requiring very large and toxic doses of drugs such as tacrolimus ${ }^{12}$, 39,40. Mimicking the natural (and temporary) suppressive function of nerves on the immune response to promote survival of VCA, (or even that of more traditional solid organ transplants) has never been tested previously in either preclinical or clinical settings.

In non- $\beta_{2}-\mathrm{AR}$ agonist treated animals, $\mathrm{CD}^{+} \mathrm{T}$ and $\mathrm{CD} 8^{+} \mathrm{T}$ cells were increased significantly in transplanted grafts at the time of rejection. Treatment with $\beta_{2}$-AR agonist treatment was associated with significantly fewer numbers of infiltrated $\mathrm{T}$ cell, and decreased EM T and Th1 cell populations in recipients corresponding to the prolonged survival benefit. Although several clinical and preclinical studies have shown that Tregs modulate immune responses and that a high level of Treg population can predict better prognosis after solid organ and hematopoietic cell transplantation ${ }^{41}$, in our VCA model, increased numbers of Tregs were detected in the presence of strong immune responses after transplant. Thus, recipients with greater levels of Treg populations showed severe gross rejection at early time points and eventual resolution of the population in the recipient's blood and grafts after severe gross rejection was well underway. This suggests that Treg levels may influence or predict rejection of highly antigenic VCA grafts as opposed to those used in solid organ transplants, particularly at early time points. VCA was also associated with an increased immunosuppressive MDSC population compared to the non-transplanted animals, and a significant increase in MDSC was noted with $\beta_{2}$-agonist treatment. This increase appeared consistent with $\beta_{2}$-agonist effects in GVHD after BMT $^{29}$, and may be a more potent contributor to immunosuppression than Treg induction. 
In terms of immune modulatory impact of addition of a $\beta_{2}$-AR agonist, terbutaline delayed rejection responses in association with significant decreases in $\mathrm{CD}^{+} / \mathrm{CD} 8^{+} \mathrm{EM} \mathrm{T}$ and Th1 cell populations, cytokines and chemokines such as IFN- $\gamma$, IL- 6 , TNF- $\alpha$, CXCL-1/10 and CCL3/4/5/7 in recipients. Additionally, $\beta_{2}-\mathrm{AR}$ agonist treatment increased the antiinflammatory cytokine, IL-13, which was associated with concomitant down-regulation of TNF- $\alpha$ production, a phenomenon observed in other studies ${ }^{42,43}$. IL18, CCL2 and CCL11 were particularly noted as unresponsive to $\beta_{2}$-agonist treatment indicating that these cytokine and chemokines could be additional targets to suppress rejection responses after VCA.

$\beta_{2}$-AR signal modulation either in recipients or donors was sufficient to delay gross rejection responses, but the modulation of donor cell $\beta_{2}$-AR resulted in a more potent effect. Specifically, donor cell AR modulation in tissue stromal cells was necessary to suppress recipient $\mathrm{T}$ cell trafficking into grafts. Leukocyte extravasation is a prerequisite for acute rejection in grafts, and their migration into the tissue requires the expression of adhesion molecules on the surface of activated endothelium ${ }^{44,45}$. The endothelial adhesion molecules ICAM-1 and VCAM-1 are known as the central mediators of leukocyte adhesion to and transmigration across the endothelium ${ }^{36}$, and $\beta_{2}$-AR agonist suppressed ICAM-1 and VCAM1 expression with concomitant decreased $\mathrm{T}$ cell trafficking into grafts. Of note, ICAM-2 mediators by massive up-regulation of adhesion receptors such as ICAM-1 and VCAM-1, whereas ICAM-2 decreases ${ }^{46-48}$. A possible explanation for our observed increase in ICAM-2 is that it might represent a compensatory mechanism for decreased ICAM-1 or an additional effect of $\beta_{2}$-AR modulation. The $\beta_{2}$-AR agonist, terbutaline, stimulated angiogenesis on endothelial cells derived from the central nervous system ${ }^{49}$, and ICAM-2 has been associated with this process ${ }^{50}$. By regulating ICAM-2 and increasing angiogenesis, $\beta_{2}$-agonist treatment 
could reduce ischemic injury in harvested organs. Graft salvage effects of $\beta_{2}$-agonist suggest that regulation of endothelial adhesion molecules partially contributes for the prevention of chronic rejection after VCA (Fig. 4). Another possible mechanism underlying benefits of a $\beta_{2}$ agonist is that it can increase cAMP (cyclic adenosine monophosphate) levels; cAMP is known as a potent negative regulator in $\mathrm{T}$ cells, which dampens $\mathrm{T}$-cell immune function through the $\mathrm{cAMP} /$ protein kinase A signaling pathway ${ }^{51}$.

$\beta_{2}$-AR activation in donor BM cells was necessary for the observed immunosuppressive cell (HPC) was replaced by the recipient's HPC within 5 days after VCA in our model (Supplementary Fig. 2), it is likely that a transient mixed chimerism developed in the recipients which was sufficient for the induction of allograft tolerance ${ }^{52,53}$. While the study of transplant tolerance is beyond the scope of this study, $\beta_{2}$-agonist treatment could be a mechanism to facilitate the induction of tolerance and could replace at least some of the more toxic immunosuppressive drugs currently being used.

Preconditioning donors with $\beta_{2}$-agonist suppressed $\mathrm{T}$ cell trafficking into grafts resulting in delayed acute rejection responses, even though systemic immunosuppressive effects such as decreases in $\mathrm{CD} 4^{+} / \mathrm{CD}^{+}$memory $\mathrm{T}$ and $\mathrm{Th} 1$ cell populations were missing. Interestingly, in a previous study, cadaveric kidney donors who were treated with dopamine and NE to maintain their BP and HR while intensive cares resulted in reduced acute rejection and improved graft survival after transplantation ${ }^{54,55}$, and our current findings may be the mechanism for this observation. $\beta_{2}$-agonist addition to preservation solutions may be a relatively simple measure to improve organ transplantation, in addition to treatment of recipients.

One problem with our approach is that terbutaline is a relatively short acting $\beta_{2}$-agonist.

377 It is likely - that the effects of $\beta_{2}$-AR modulation with longer acting agonists (e.g., bambuterol, 
salmeterol) could be superior to terbutaline. Another limitation is that our study is focused upon $\mathrm{T}$ lymphocytes and their role in graft rejection. Even though current immunosuppressive therapies for solid organ transplantation appear to be dominated by T cell mechanisms (making the information presented here quite pertinent), other immune cell subtypes including components of the innate immune system and B cells are also associated with graft rejection and may be contributory to some of the observed findings. These additional mechanisms should be addressed in future studies.

In conclusion, there is a significant need to reduce the amounts of standard immunosuppressant drugs currently being given to patients receiving VCA. We have demonstrated here that by targeting adrenergic stress pathways ordinarily used by nerves of the autonomic nervous system, we could not only delay rejection responses but more importantly, allow for reduction of the dose of a standard immunosuppressive drug in various VCA scenarios. We have also identified several relevant mechanisms by which this prolongation of the survival of VCA occurs. While future studies will certainly further optimize the dose and scheduling of applications of $\beta$-agonists to prolong graft survival, this approach could be tested immediately as a safe strategy for reducing the amount of highly toxic immunosuppressive drugs given to patients requiring VCA.

\section{Methods}

Mice

Female C57BL/6 (H-2 $\left.{ }^{\mathrm{b}}\right), \mathrm{C} 57 \mathrm{BL} / 6\left(\mathrm{H}-2^{\mathrm{b}}, \mathrm{CD} 45.1\right)$, and BALB/c $\left(\mathrm{H}-2^{\mathrm{d}}\right)$ mice aged 7-8 weeks were purchased from Charles River (Kingston, NY) and The Jackson Laboratory (Bar Harbor, ME) as recipients and donors respectively. $\beta_{2}$-AR KO mice on BALB/c and C57BL/6 background are bred in-house from an established colony. Mice were fed a standard laboratory diet and housed under standard light and accommodation conditions. All animal experiments 
were done with the approval of Roswell Park Comprehensive Cancer Center Animal Care and Use Committee IACUC.

VCA surgery

All procedures were carried out under sterile conditions by one investigator (MK) as described in our previous published work ${ }^{32}$. Briefly, a donor's abdominal aorta and femoral vein were used for revascularization with a recipient's common carotid artery and external jugular vein respectively using a non-suture cuff technique. We used BALB/c background strain as donors and $\mathrm{C} 57 \mathrm{BL} / 6$ background strain as recipients because we have revealed that a BALB/c strain had a higher anatomical mutation rate on the Circle of Willis than C57BL/6 $\operatorname{strain}^{32}$.

\section{Drug treatments}

Immunosuppression was induced in mice using tacrolimus (Sigma-Aldrich, St. Louis, MO) in doses of 2 or $4 \mathrm{mg} / \mathrm{kg}$ (in DMSO; Sigma-Aldrich, St. Louis, MO) injected subcutaneously with a micro syringe (Hamilton, Reno, NV) daily. $\beta_{2}$-AR activation was achieved using daily intraperitoneal injections of $2 \mathrm{mg}$ terbutaline (200 $\mu \mathrm{L}$ in DPBS; Corning Inc., Corning, NY). The same DPBS was used for vehicle.

\section{HR and BP measurement}

A noninvasive blood pressure monitoring system (CODA, Kent Scientific corporation, Torrington, CT) was used to measure HR and BP in mice ${ }^{56}$. Mice were acclimated with the system for 10 days prior to initiating experimental measurements.

\section{Blood collection}

Blood was collected from the right superficial temporal vein (STV) using a sterile 5$\mathrm{mm}$ animal lancet (Medipoint, INC., Mineola, NY) after anesthesia induction. The STV is a large vessel positioned posterior to the eye, which can be traced one eye length back and one eye width up from the sebaceous gland ${ }^{57}$. Concentrations of tacrolimus were measured in 
plasma prepared from the collected blood samples by VITROS 5.1 FS (Ortho Clinical

Diagnostics, Inc., Rochester, NY).

Following standard euthanasia, grafted tissue was harvested and fixed in $10 \%$

formaldehyde (Thermo Scientific, Waltham, MA), and then tissue was embedded in paraffin.

433 Formalin fixed paraffin sections were cut at $4 \mu \mathrm{m}$, placed on charged slides, and dried at $60^{\circ} \mathrm{C}$ for one hour. Slides were cooled to room temperature and added to the Leica Bond Rx, where they were deparaffinized with Bond Dewax Solution (Leica, Allendale, NJ) and rinsed in water. Bond Epitope Retrieval 2 (Leica, Allendale, NJ) was used for target retrieval for 30 minutes. Slides were blocked using peroxide block from Bond Polymer Refine Detection kit (Leica, Allendale, NJ) for 5 minutes. Slides were incubated with CD4 Antibody (Abcam, Cambridge, United Kingdom) at 1/1000 or CD8 (Abcam, Cambridge, United Kingdom) at 1/1000 or FOXP3 (Boster Biological Technology, Pleasanton, CA) at 1/50 for 20 minutes followed by Rabbit Envision (Agilent Technologies, Santa Clara, CA) for 30 minutes. DAB (Diaminobenzidine) from the Bond Polymer Refine Detection kit (Leica, Allendale, NJ) was applied for 10 minutes for visualization. Slides were counterstained with Hematoxylin from the Bond Polymer Refine Detection kit (Leica, Allendale, NJ) for 8 minutes then placed into water. After removing slides from the Bond they were dehydrated, cleared, and cover-slipped.

\section{Immunofluorescence histology}

OCT (Sakura Finetek, Tokyo, Japan)-embedded tissue cryosections ( $9 \mu \mathrm{m}$-thick) were fixed at $-20^{\circ} \mathrm{C}$ in methanol/acetone $(3: 1)$, blocked using $10 \%$ serum, and stained with primary antibodies anti-mouse ICAM-1, ICAM-2, VCAM-1 antibodies (BD Biosciences, San Jose, CA) and anti-mouse CD31 antibody (Abcam, Cambridge, United Kingdom). Images of at least 5 consecutive fields (unit area of each field, $0.34 \mathrm{~mm}^{2}$ ) were captured by observers blinded to sample identity. Identical exposure times and image settings were used within each experiment. 
Images were analyzed with ImageJ software (NIH, Bethesda, MD) for determination of the

454

455

456

457

458

459

460

461

462

463

464

465

466

467

468

469

470

471

472

473

474

475

476

477

relative fluorescence staining intensity; regions of interest were defined based on CD31

fluorescence, and each pixel in identified regions was assigned a fluorescence intensity value (based on a scale from 0 to 255 ).

\section{Flow Cytometry}

Spleens were mechanically disrupted and directly passed through a $70 \mu \mathrm{m}$ nylon cell strainer (Alkali Scientific, Pompano Beach, FL) followed by lysing red blood cells with hypotonic lysis buffer (Gibco, Gaithersburg, MD). Single-cell suspensions were created from whole tissue transplanted grafts using the Medimachine tissue disruption system (Beckton Dickinson, Franklin Lakes, NJ), followed by leukocyte isolation using Lymphoprep (Stemcell Technologies, Vancouver, Canada). Prepared cells were stained with different antibodies for extracellular and intracellular markers. Antibodies of CD45 (BUV395, clone; 30-F11), CD45.1 (BUV395, clone; 20), CD45.2 (BV605, clone; 104), CD3 (Alexa Fluor 700, 17A2), CD4 (PerCp, clone; RM4.5), CD8 (Alexa Fluor 488, clone; 53-6.7), CD25 (APC, clone; PC61), CD44 (V450, clone; IM7), CD62L (PE, clone; MEL-14), Foxp3 (PE, clone; MF23), IFN- $\gamma$ (PE-CF594, clone; XMG1.2), IL4 (APC, clone; 11B11), and IL17 (BV421, clone; TC1118H10) were used (BD Bioscience, San Jose, CA). All data were collected on an LSR Fortessa flow cytometer (BD Biosciences, San Jose, CA) and analyzed with WinList 9.0 software (Verity Software House, Topsham, ME).

\section{Luminex assay}

Plasma was prepared from collected blood after a 20 -minute centrifuge at $800 \mathrm{~g}$ without using a brake. Mouse 11-plex cytokine and 9-plex chemokine were performed by Flow and Imaging Cytometry Shared Resource, Luminex Division at Roswell Park Comprehensive Cancer Center per the manufacturer's instructions (Invitrogen, Carlsbad, CA).

\section{Bone marrow chimeras}


479 Recipient mice were lethally irradiated with 8.0 Gy of total body irradiation (Cesium ${ }^{137}$ source).

480 One day after irradiation, BM was reconstituted with the intravenous injection via a tail vein 481 of $10 \times 10^{6}$ donor cells. Reconstituted mice were used 8 weeks after BMT.

482 Assessment of rejection grade Gross rejection grades and pathology rejection grades were evaluated by M.K. and P.N.B. respectively based on the Banff 2007 working classification of skin-containing

485

486

487

488

489

490

491

492

493

494

495

496

497

498

499

500

501

502 composite tissue allograft pathology $\mathrm{y}^{35}$.

\section{Statistical analysis}

Comparison between groups were performed using Student's t test, and statistical significance was accepted with $\mathrm{p}<0.05$. Log-rank (Mantel-Cox) test was used for survival comparisons between groups using GraphPad Prism, Version 8 software (GraphPad Software, Inc., La Jolla, CA).

(1)

2

(1)


504 Fig. 1. A schematic illustration of our VCA model and the safety of a selective $\beta_{2}$-adrenergic 505 receptor (AR) agonist drug, terbutaline.

506 Fig. 2. Pathologic findings 5 and 7 days after VCA with either vehicle or $\beta_{2}$-agonist injections.

507 Fig. 3. The composition of donor's and recipient's leukocytes in donor grafts and recipient 508 blood 5 and 7 days after VCA.

509 Fig. 4. Numbers of Foxp $3^{+}$cell in transplanted grafts and the composition of Treg $510\left(\mathrm{CD} 4^{+} \mathrm{CD} 25^{+} \mathrm{Foxp}^{+}\right)$population with fTac injections after VCA.

511 Fig. 5. Preconditioning in donors with $\beta_{2}$-AR agonist delays rejection responses through 512 suppression of $\mathrm{T}$ cell trafficking in the grafts.

513 Table S1. Visual and histologic grading system for assessment of rejection after VCA 514 


\section{References:}

5291 Fleming, M. E., Bharmal, H. \& Valerio, I. Regenerative medicine applications in $530 \quad$ combat casualty care. Regen Med 9, 179-190, doi:10.2217/rme.13.96 (2014).

5312 Fleming, M., Waterman, S., Dunne, J., D'Alleyrand, J. C. \& Andersen, R. C. 532 Dismounted complex blast injuries: patterns of injuries and resource utilization 533 associated with the multiple extremity amputee. J Surg Orthop Adv 21, 32-37 (2012).

5343 Gawande, A. Casualties of war--military care for the wounded from Iraq and 535 Afghanistan. N Engl J Med 351, 2471-2475, doi:10.1056/NEJMp048317 (2004).

5364 Petit, F., Minns, A. B., Dubernard, J. M., Hettiaratchy, S. \& Lee, W. P. Composite 537 tissue allotransplantation and reconstructive surgery: first clinical applications. Annals 538 of surgery 237, 19-25, doi:10.1097/01.SLA.0000041228.23111.30 (2003).

5395 Siemionow, M. \& Kulahci, Y. Facial transplantation. Seminars in plastic surgery 21, 540 259-268, doi:10.1055/s-2007-991196 (2007).

5416 Devauchelle, B. et al. First human face allograft: early report. Lancet 368, 203-209, 542 doi:10.1016/S0140-6736(06)68935-6 (2006).

5437 Dubernard, J. M., Owen, E. R., Lanzetta, M. \& Hakim, N. What is happening with hand $544 \quad$ transplants. Lancet 357, 1711-1712, doi:10.1016/S0140-6736(00)04846-7 (2001).

5458 Gilbert, R. Transplant is successful with a cadaver forearm. Med Trib Med News, 20$54623(1964)$.

5479 Gupta, A., Kumer, S. \& Kaplan, B. Novel immunosuppressive strategies for composite 548 tissue allografts. Current opinion in organ transplantation 19, 552-557, 549 doi:10.1097/MOT.0000000000000135 (2014).

55010 Dubernard, J. M. et al. Human hand allograft: report on first 6 months. Lancet 353, 551 1315-1320, doi:10.1016/S0140-6736(99)02062-0 (1999). 
55211 Jones, J. W., Gruber, S. A., Barker, J. H. \& Breidenbach, W. C. Successful hand 553 transplantation. One-year follow-up. Louisville Hand Transplant Team. N Engl J Med $554 \quad 343,468-473$, doi:10.1056/NEJM200008173430704 (2000).

55512 Kueckelhaus, M. et al. Vascularized composite allotransplantation: current standards 556 and novel approaches to prevent acute rejection and chronic allograft deterioration. Transplant international : official journal of the European Society for Organ Transplantation 29, 655-662, doi:10.1111/tri.12652 (2016).

55913 Petruzzo, P. et al. The International Registry on Hand and Composite Tissue 560 Transplantation. Transplantation 90, 1590-1594, doi:10.1097/TP.0b013e3181ff1472 (2010).

56214 Basu, A. et al. Overexpression of vascular endothelial growth factor and the 563 development of post-transplantation cancer. Cancer research 68, 5689-5698, doi:10.1158/0008-5472.CAN-07-6603 (2008).

56515 Gallagher, M. P. et al. Long-term cancer risk of immunosuppressive regimens after kidney transplantation. Journal of the American Society of Nephrology : JASN 21, 852858, doi:10.1681/ASN.2009101043 (2010). in The Daily Telegraph (2016). host defense: Implications for transplantation. American journal of transplantation : official journal of the American Society of Transplantation and the American Society of Transplant Surgeons 18, 556-563, doi:10.1111/ajt.14515 (2018).

57318 Smith, S. M. \& Vale, W. W. The role of the hypothalamic-pituitary-adrenal axis in neuroendocrine responses to stress. Dialogues Clin Neurosci 8, 383-395 (2006).

57519 Herman, J. P. et al. Regulation of the Hypothalamic-Pituitary-Adrenocortical Stress 576 Response. Compr Physiol 6, 603-621, doi:10.1002/cphy.c150015 (2016). 
57720 Sundman, E. \& Olofsson, P. S. Neural control of the immune system. Advances in $578 \quad$ physiology education 38, 135-139 (2014).

57921 Forsythe, P. The nervous system as a critical regulator of immune responses underlying $580 \quad$ allergy. Current pharmaceutical design 18, 2290-2304 (2012).

58122 Madva, E. N. \& Granstein, R. D. Nerve-derived transmitters including peptides influence cutaneous immunology. Brain, behavior, and immunity 34, 1-10, doi:10.1016/j.bbi.2013.03.006 (2013).

23 Padgett, D. A. \& Glaser, R. How stress influences the immune response. Trends in immunology 24, 444-448 (2003).

24 Glaser, R. \& Kiecolt-Glaser, J. K. Stress-induced immune dysfunction: implications for health. Nature reviews. Immunology 5, 243-251, doi:10.1038/nri1571 (2005).

Eng, J. W. et al. Housing temperature-induced stress drives therapeutic resistance in murine tumour models through beta2-adrenergic receptor activation. Nat Commun $\mathbf{6}$, 6426, doi:10.1038/ncomms7426 (2015).

Bucsek, M. J. et al. beta-Adrenergic Signaling in Mice Housed at Standard Temperatures Suppresses an Effector Phenotype in CD8(+) T Cells and Undermines Checkpoint Inhibitor Therapy. Cancer research 77, 5639-5651, doi:10.1158/00085472.CAN-17-0546 (2017).

27 Qiao, G. et al. beta-Adrenergic signaling blocks murine CD8(+) T-cell metabolic $598 \quad$ (2019). reprogramming during activation: a mechanism for immunosuppression by adrenergic stress. Cancer Immunol Immunother 68, 11-22, doi:10.1007/s00262-018-2243-8 Response. Front Immunol 9, 164, doi:10.3389/fimmu.2018.00164 (2018). 
602

603

604

605

606

607

608

609

610

611

612

613

614

615

616

617

618

619

620

621

622

623

624

625

29 Mohammadpour, H. et al. beta2 adrenergic receptor-mediated signaling regulates the immunosuppressive potential of myeloid-derived suppressor cells. J Clin Invest 129, 5537-5552, doi:10.1172/JCI129502 (2019).

30 Leigh, N. D. et al. Housing Temperature-Induced Stress Is Suppressing Murine Graftversus-Host Disease through beta2-Adrenergic Receptor Signaling. J Immunol 195, 5045-5054, doi:10.4049/jimmunol.1500700 (2015).

31 Mohammadpour, H. et al. beta2-Adrenergic receptor activation on donor cells ameliorates acute GvHD. JCI Insight 5, doi:10.1172/jci.insight.137788 (2020).

32 Kim, M., Fisher, D. T., Powers, C. A., Repasky, E. A. \& Skitzki, J. J. Improved Cuff Technique and Intraoperative Detection of Vascular Complications for Hind Limb Transplantation in Mice. Transplant Direct 4, e345, doi:10.1097/TXD.0000000000000756 (2018).

33 Vasilic, D. et al. Risk assessment of immunosuppressive therapy in facial $\begin{array}{lllll}\text { transplantation. } & \text { Plast } & \text { Reconstr }\end{array}$ doi:10.1097/01.prs.0000270316.33293.ec (2007).

34 Zhao, X. et al. Arterial Pressure Monitoring in Mice. Curr Protoc Mouse Biol 1, 105122, doi:10.1002/9780470942390.mo100149 (2011).

35 Cendales, L. C. et al. The Banff 2007 working classification of skin-containing composite tissue allograft pathology. American journal of transplantation : official journal of the American Society of Transplantation and the American Society of Transplant Surgeons 8, 1396-1400, doi:10.1111/j.1600-6143.2008.02243.x (2008).

36 Panes, J., Perry, M. \& Granger, D. N. Leukocyte-endothelial cell adhesion: avenues for therapeutic intervention. Br J Pharmacol 126, 537-550, doi:10.1038/sj.bjp.0702328 (1999). 
62637 Olson, T. S. \& Ley, K. Chemokines and chemokine receptors in leukocyte trafficking. Am J Physiol Regul Integr Comp Physiol 283, R7-28, doi:10.1152/ajpregu.00738.2001

628 (2002).

38 Barisione, G., Baroffio, M., Crimi, E. \& Brusasco, V. Beta-Adrenergic Agonists. Pharmaceuticals (Basel) 3, 1016-1044, doi:10.3390/ph3041016 (2010).

39 Schneeberger, S. et al. Achievements and challenges in composite tissue allotransplantation. Transplant international : official journal of the European Society for Organ Transplantation 24, 760-769, doi:10.1111/j.1432-2277.2011.01261.x (2011).

40 Howsare, M., Jones, C. M. \& Ramirez, A. M. Immunosuppression maintenance in vascularized composite allotransplantation: what is just right? Current opinion in organ transplantation 22, 463-469, doi:10.1097/MOT.0000000000000456 (2017).

638

41 Wood, K. J. \& Sakaguchi, S. Regulatory T cells in transplantation tolerance. Nature reviews. Immunology 3, 199-210, doi:10.1038/nri1027 (2003). in normal human monocytes. J Immunol 155, 3145-3151 (1995). (2007). Albanesi, C. et al. IL-4 and IL-13 negatively regulate TNF-alpha- and IFN-gamma(SOCS)-1, and SOCS-3. J Immunol 179, 984-992, doi:10.4049/jimmunol.179.2.984

Issekutz, A. C., Meager, A., Otterness, I. \& Issekutz, T. B. The role of tumour necrosis factor-alpha and IL-1 in polymorphonuclear leucocyte and T lymphocyte recruitment to joint inflammation in adjuvant arthritis. Clin Exp Immunol 97, 26-32, doi:10.1111/j.1365-2249.1994.tb06574.x (1994). 

the crossroads of cell signalling and inflammatory disease. Biochim Biophys Acta 1843, 2563-2582, doi:10.1016/j.bbamcr.2014.05.014 (2014).

653

46 McLaughlin, F. et al. Tumor necrosis factor (TNF)-alpha and interleukin (IL)-1beta down-regulate intercellular adhesion molecule (ICAM)-2 expression on the endothelium. Cell Adhes Commun 6, 381-400, doi:10.3109/15419069809109147 (1998).

657

47 Lehmann, J. C. et al. Overlapping and selective roles of endothelial intercellular adhesion molecule-1 (ICAM-1) and ICAM-2 in lymphocyte trafficking. J Immunol 171, 2588-2593, doi:10.4049/jimmunol.171.5.2588 (2003).

Lyck, R. \& Enzmann, G. The physiological roles of ICAM-1 and ICAM-2 in neutrophil 661 migration into tissues. Curr Opin Hematol

22, 53-59,

662 doi:10.1097/MOH.0000000000000103 (2015).

49 Lemmens, S., Kusters, L., Bronckaers, A., Geurts, N. \& Hendrix, S. The beta2664 Adrenoceptor Agonist Terbutaline Stimulates Angiogenesis via Akt and ERK Signaling. J Cell Physiol 232, 298-308, doi:10.1002/jcp.25483 (2017).

Huang, M. T. et al. Endothelial intercellular adhesion molecule (ICAM)-2 regulates

667 angiogenesis. Blood 106, 1636-1643, doi:10.1182/blood-2004-12-4716 (2005).

668

51 Vang, T. et al. Activation of the COOH-terminal Src kinase (Csk) by cAMP-dependent protein kinase inhibits signaling through the T cell receptor. J Exp Med 193, 497-507, doi:10.1084/jem.193.4.497 (2001).

67152 Sachs, D. H., Kawai, T. \& Sykes, M. Induction of tolerance through mixed chimerism. Cold Spring Harb Perspect Med 4, a015529, doi:10.1101/cshperspect.a015529 (2014).

67353 Oura, T., Hotta, K., Cosimi, A. B. \& Kawai, T. Transient mixed chimerism for allograft 674 tolerance. Chimerism 6, 21-26, doi:10.1080/19381956.2015.1111975 (2015). 
67554 Schnuelle, P., Lorenz, D., Mueller, A., Trede, M. \& Van Der Woude, F. J. Donor 676 catecholamine use reduces acute allograft rejection and improves graft survival after

677

678

679

680

681

682

683

684

685

686

687

688

689

690

691

692

693

694

695

696

697

698 cadaveric renal transplantation. Kidney Int 56, 738-746, doi:10.1046/j.15231755.1999.00567.x (1999).

55 Schnuelle, P. et al. Impact of donor dopamine on immediate graft function after kidney transplantation. American journal of transplantation : official journal of the American Society of Transplantation and the American Society of Transplant Surgeons 4, 419426, doi:10.1111/j.1600-6143.2004.00331.x (2004).

56 Wang, Y., Thatcher, S. E. \& Cassis, L. A. Measuring Blood Pressure Using a Noninvasive Tail Cuff Method in Mice. Methods Mol Biol 1614, 69-73, doi:10.1007/978-1-4939-7030-8_6 (2017).

57 Regan, R. D., Fenyk-Melody, J. E., Tran, S. M., Chen, G. \& Stocking, K. L. Comparison of Submental Blood Collection with the Retroorbital and Submandibular Methods in Mice (Mus musculus). J Am Assoc Lab Anim Sci 55, 570-576 (2016).

(1) 
699 Acknowledgement: The authors would like to thank Drs. Michelle Appenheimer, Bonnie 700 Hylander and Hemn Mohammadpour for their constructive criticism of the manuscript.

701 Funding: This research was supported by R21AI136367-01A1 from NIH NIAID and Cancer

702 Center Support Grant P30CA06156.

703 Author contributions:

704 Participated in research design: M.K. and E.A.R.

705 Participated in the writing of the paper: M.K., E.A.R., and J.J.S.

706 Participated in data acquisition: M.K. and D.T.F.

707 Participated in data analysis: M.K., P.N.B., U.S., and D.T.F.

708 Participated in data interpretation: M.K., P.N.B., U.S., J.J.S., and E.A.R.

709 Participated in critical revision: M.K., J.J.S., and E.A.R

710 All authors discussed results and commented on the manuscript.

711 Competing interests: The authors reported no proprietary or commercial interest in any 712 product mentioned or concept discussed in the article. 
Figures:

Fig. 1

a
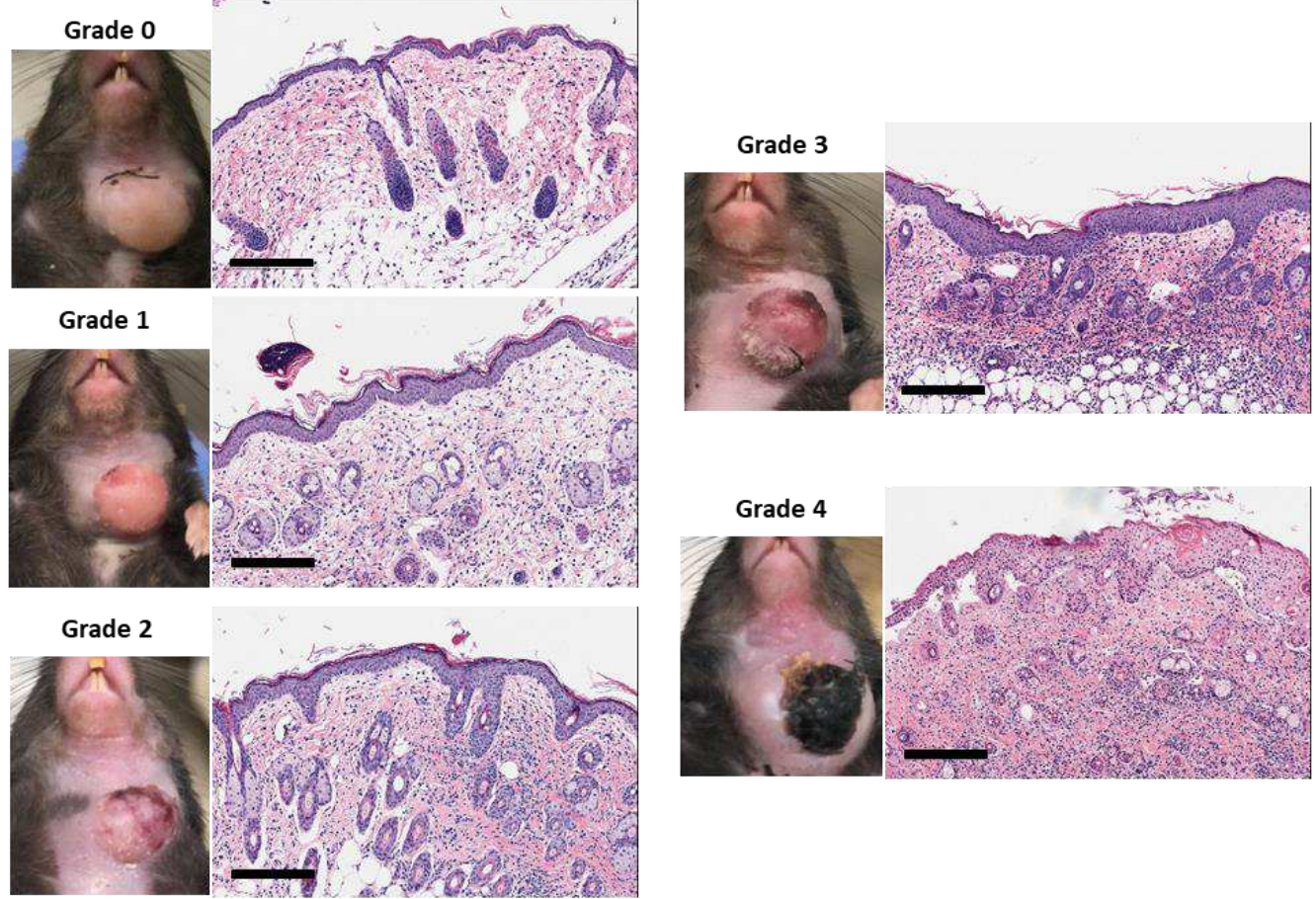

b
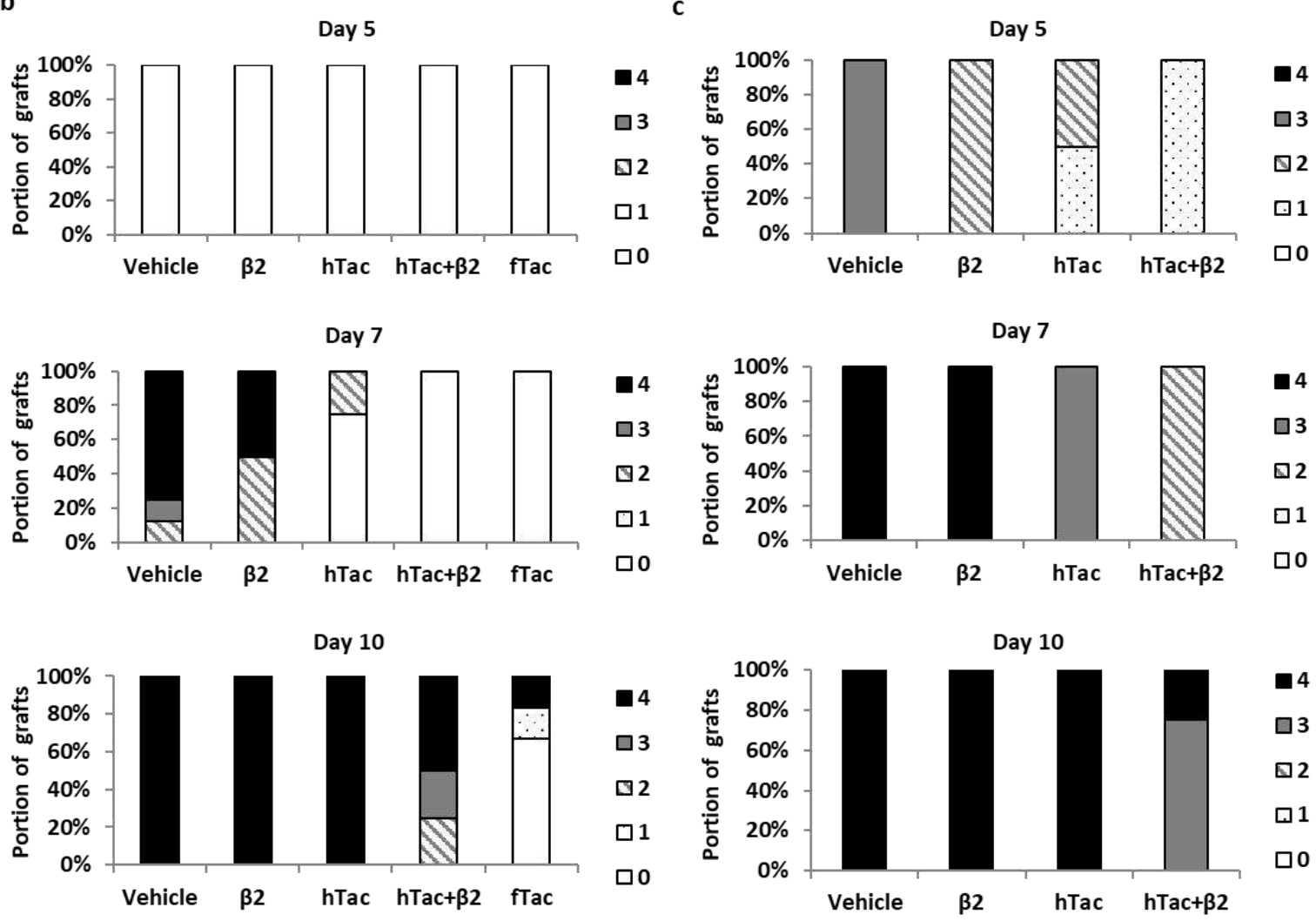

Fig. 1: $\beta_{2}-A R$ agonist delays rejection responses after VCA. a Examples of each clinical and

727 histologic rejection grade in a murine heterotopic hind limb transplant performed in a total 
729 treatments after VCA. Vehicle; $n=8, \beta_{2} ; n=4$, hTac; $n=4$, hTac $+\beta_{2} ; n=4$, fTac; $n=6$. c

730 Histologic rejection grades depending on different treatments after VCA, $n=4$ /group.

Fig. 2
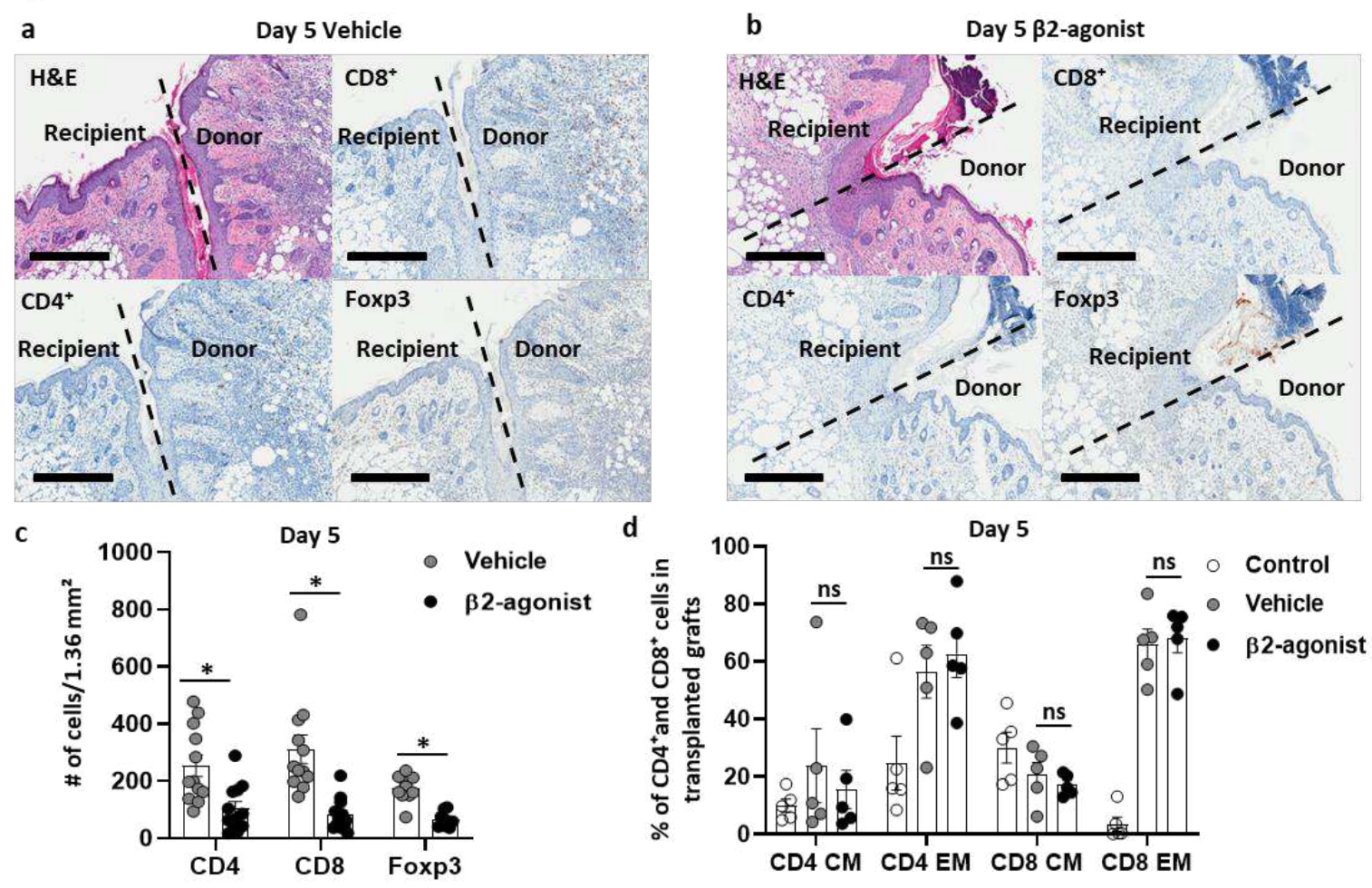

e

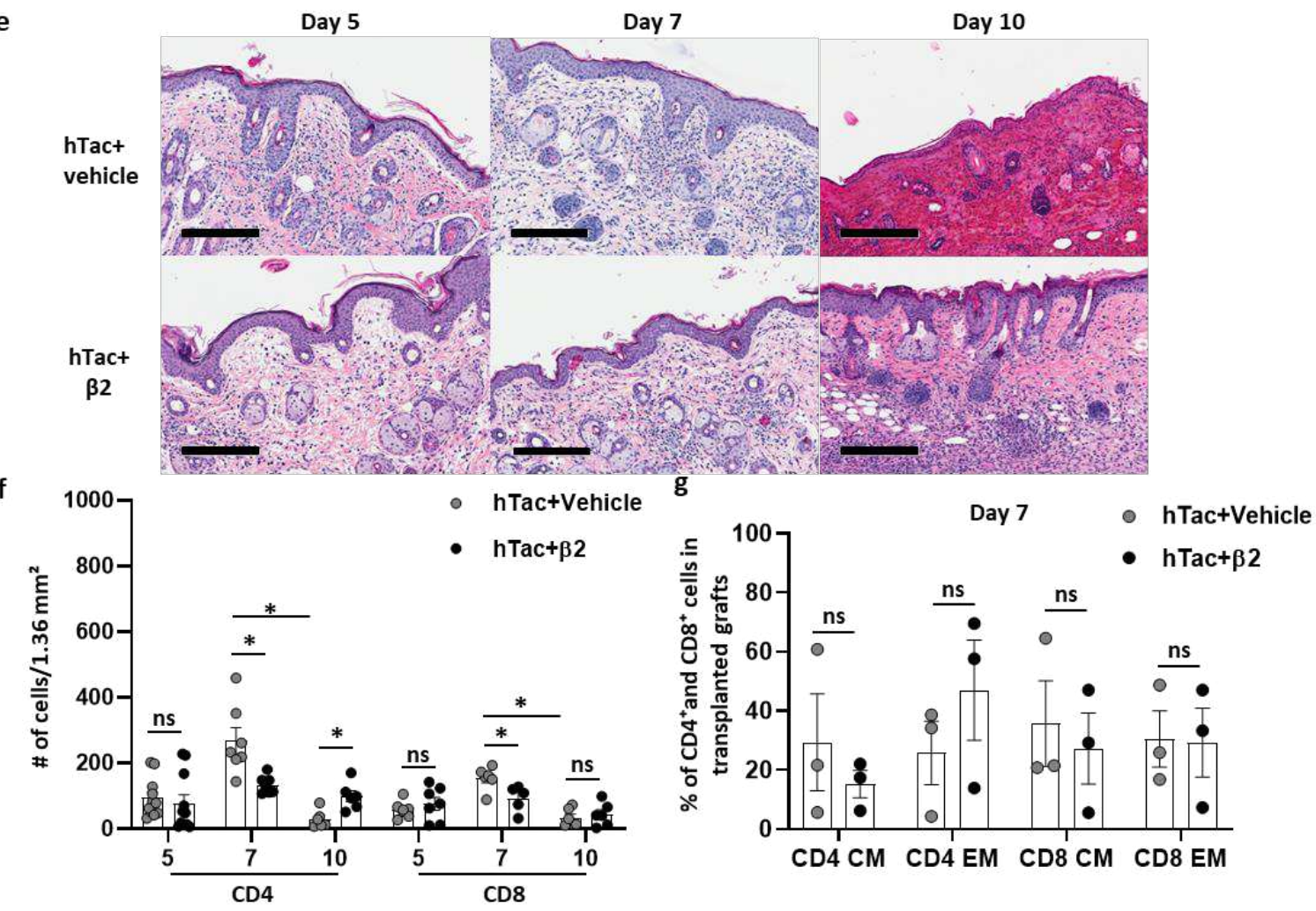


Fig. 2: $\beta_{2}$-AR agonist decreases $T$ cell infiltration in transplanted grafts along with lower numbers of Foxp3 positive cells compared to the vehicle injected group. a, b Representative figures for $\mathrm{H} \& \mathrm{E}$ and $\mathrm{IHC}$ with $\mathrm{CD} 8, \mathrm{CD} 4$, and Foxp3 antibodies with either vehicle or $\beta_{2}$-agonist treatment for 5 days. The borderline (black dotted line) differentiates recipient and donor, scale bar; $400 \mu \mathrm{m}$. c Numbers of CD4, CD8, and Foxp3 positive cells in grafts 5 days after VCA. Over 8 fields from 3 mice/group *; $p<0.05$ by Student's t test, error bar; standard error of the mean. d Compositions of $\mathrm{CD}^{+} / \mathrm{CD}^{+}$central memory $(\mathrm{CM})$ and effector memory (EM) T cell populations in transplanted grafts 5 days after VCA. Control; non-vascularized donor grafts, $n=5$, ns; not significant, ${ }^{*} ; p<0.05$ by Student's t test, error bar; standard error of the mean. e Representative figures for H\&E stain at different time points after VCA. Scale bar; $200 \mu \mathrm{m}$. f Numbers of $\mathrm{CD}^{+}$and $\mathrm{CD} 8^{+} \mathrm{T}$ cells in grafts 5, 7 and 10 days after VCA in the hTac+vehicle and the hTac $+\beta_{2}$-agonist treated groups. Over 5 fields from $n=$ 3/group, *; $p<0.05$ by Student's t test, error bar; standard error of the mean. $\mathbf{g}$ Compositions of $\mathrm{CD}^{+} / 8^{+} \mathrm{CM}$ and $\mathrm{EM} \mathrm{T}$ cell populations in transplanted grafts 7 days after treatment either with hTac or hTac $+\beta_{2}$-agonist. $n=3$, ns; not significant, error bar; standard error of the mean. 
Fig. 3
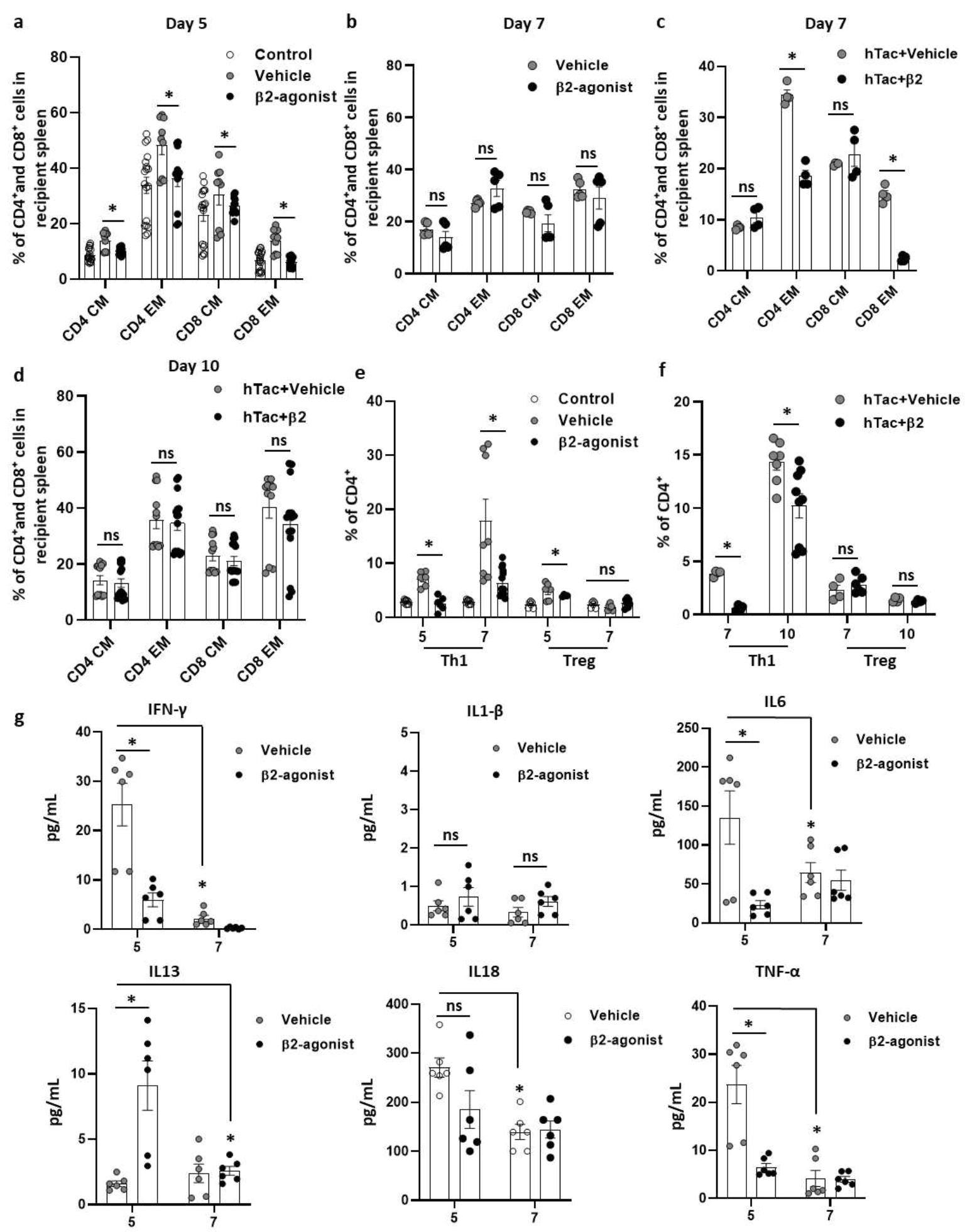

748 Fig. 3: $\boldsymbol{\beta}_{2}-\mathrm{AR}$ agonist decreases $\mathrm{CD4}^{+} / \mathrm{CD8}^{+} \mathbf{E M} \mathrm{T}$ and $\mathrm{Th1}$ cell populations, and

749 significantly decreases cytokine levels such as IFN- $\gamma$, IL-6 and TNF- $\alpha$ compared to the 750 vehicle group in recipients' blood. a, b Compositions of $\mathrm{CD} 4^{+} / \mathrm{CD} 8^{+} \mathrm{CM} / \mathrm{EM} \mathrm{T}$ cell 
751 populations in the blood 5 and 7 days either with vehicle or $\beta_{2}$-agonist after VCA without 752 tacrolimus. Day 5; $n \geq 9$, Day 7; $n=5$, control; non-transplanted animals, ns; not significant, *; $753 p<0.05$ by Student's t test, error bar; standard error of the mean. c, d Compositions of $754 \mathrm{CD}^{+} / \mathrm{CD}^{+} \mathrm{CM} / \mathrm{EM} \mathrm{T}$ cell populations in the blood 7 and 10 days with either vehicle or $\beta_{2}-$ 755 agonist after VCA with a half dose of tacrolimus (hTac). Day 7; $n=4$, Day 10; $n \geq 12$, ns; not 756 significant, *; $p<0.05$ by Student's t test, error bar; standard error of the mean. e, $\mathbf{f}$ Th1 and 757 Treg cell populations in $\mathrm{CD} 4^{+} \mathrm{T}$ cells without and with tacrolimus after VCA with either vehicle 758 or $\beta_{2}$-agonist treatments. Day $7 ; n \geq 6$, Day $10 ; n \geq 4$, ns; not significant, ${ }^{*} ; p<0.05$ by Student's $759 \mathrm{t}$ test, error bar; standard error of the mean. $\mathbf{g}$ In the setting of wild type (WT) donors and WT 760 recipients VCA without tacrolimus, various cytokine levels were analyzed 5 and 7 days after transplant by Luminex assay. $n=6$; pooled data from duplicate samples, ${ }^{*} ; p<0.05$ by Student's t test, error bar; standard error of the mean. 
Fig. 4

a

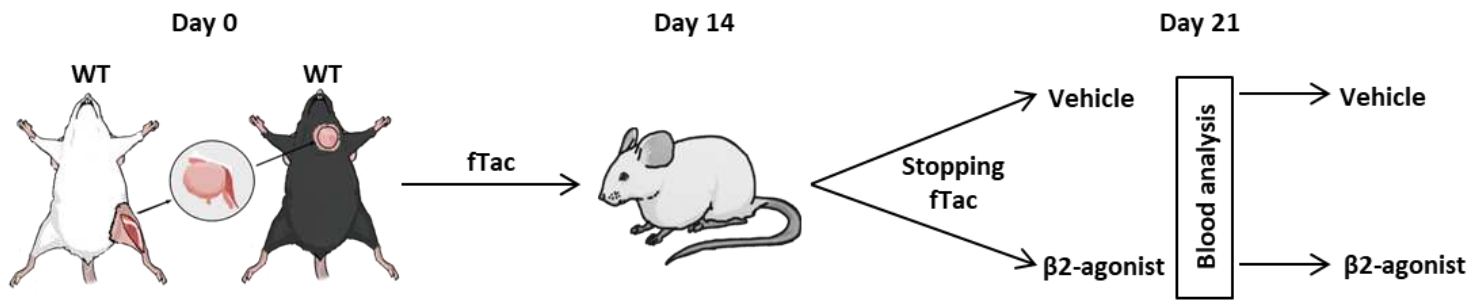

b
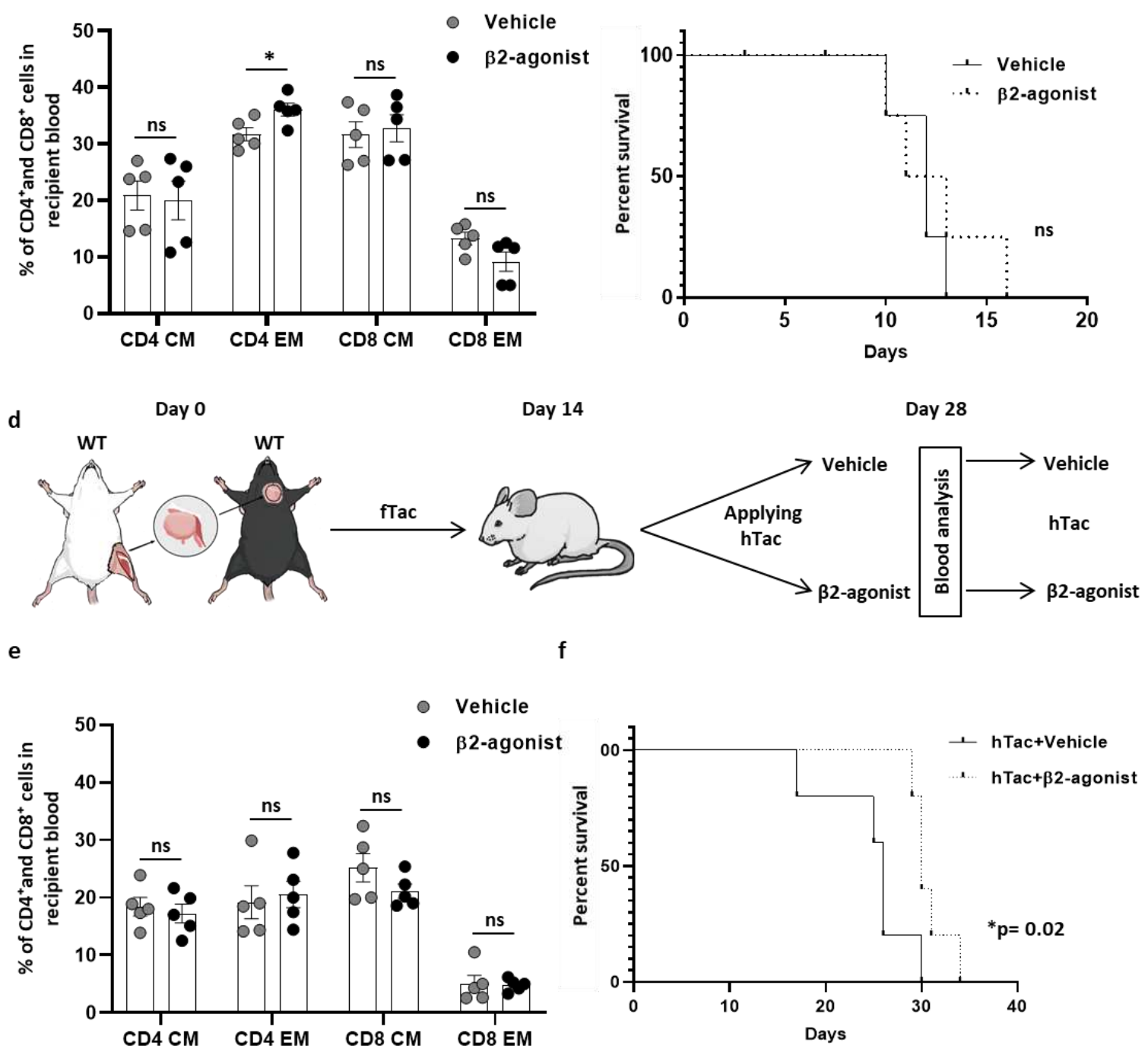

Fig. 4: $\beta_{2}-A R$ agonist injected group achieves significantly longer graft survival than the

765 vehicle injected group with a suboptimal dose of tacrolimus. a WT recipients having WT donor grafts were treated with a full dose (optimal) of tacrolimus (fTac) for 14 days, and then

767 treated with either vehicle or $\beta_{2}$-agonist after cessation of fTac. b $\mathrm{CD} 4^{+} / \mathrm{CD} 8^{+} \mathrm{CM}$ and EM T cell compositions were analyzed in the blood 21 days after VCA, 7 days after treatment with 

either vehicle or $\beta_{2}$-agonist. $n=6$, ns; not significant, *; $p<0.05$ by Student's t test, error bar; standard error of the mean. c Graft survival curves. $n=5$, ns; not significant by Log-rank test

771 using GraphPad Prism. d WT recipients were treated with a half dose (subtherapeutic) of 772 tacrolimus along with vehicle or $\beta_{2}$-agonist after 14 -day fTac injections. e $\mathrm{CD} 4^{+} / \mathrm{CD} 8^{+} \mathrm{CM}$ and 773 EM T cell compositions were analyzed in the blood 28 days after VCA, 14 days after treatment 774 with either vehicle or $\beta_{2}$-agonist. $n=5$, ns; not significant by Student's t test, error bar; standard 775 error of the mean. f Graft survival curves. $n=5, * ; p<0.05$ by Log-rank test with GraphPad 776 Prism. 
Fig. 5
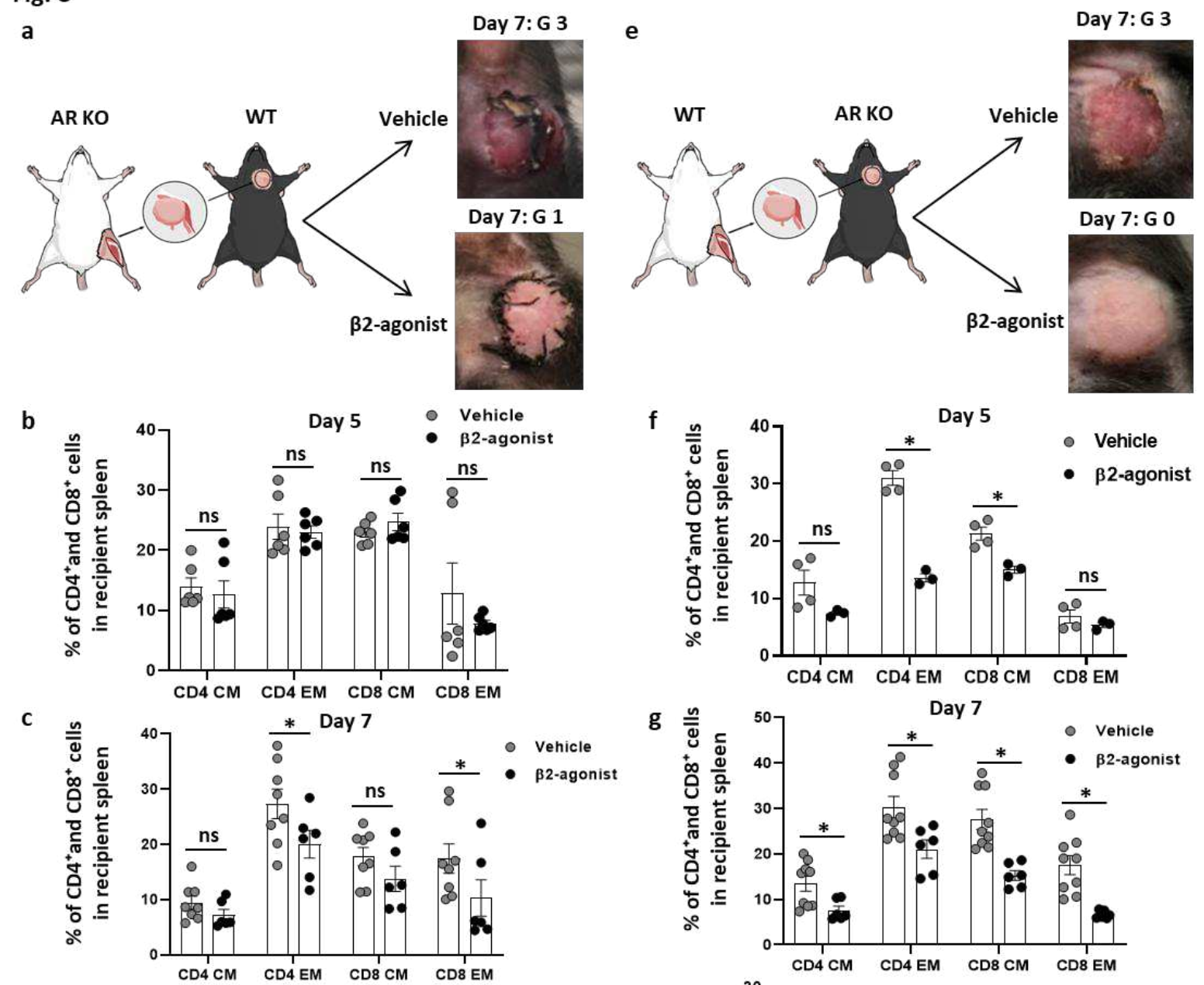

d
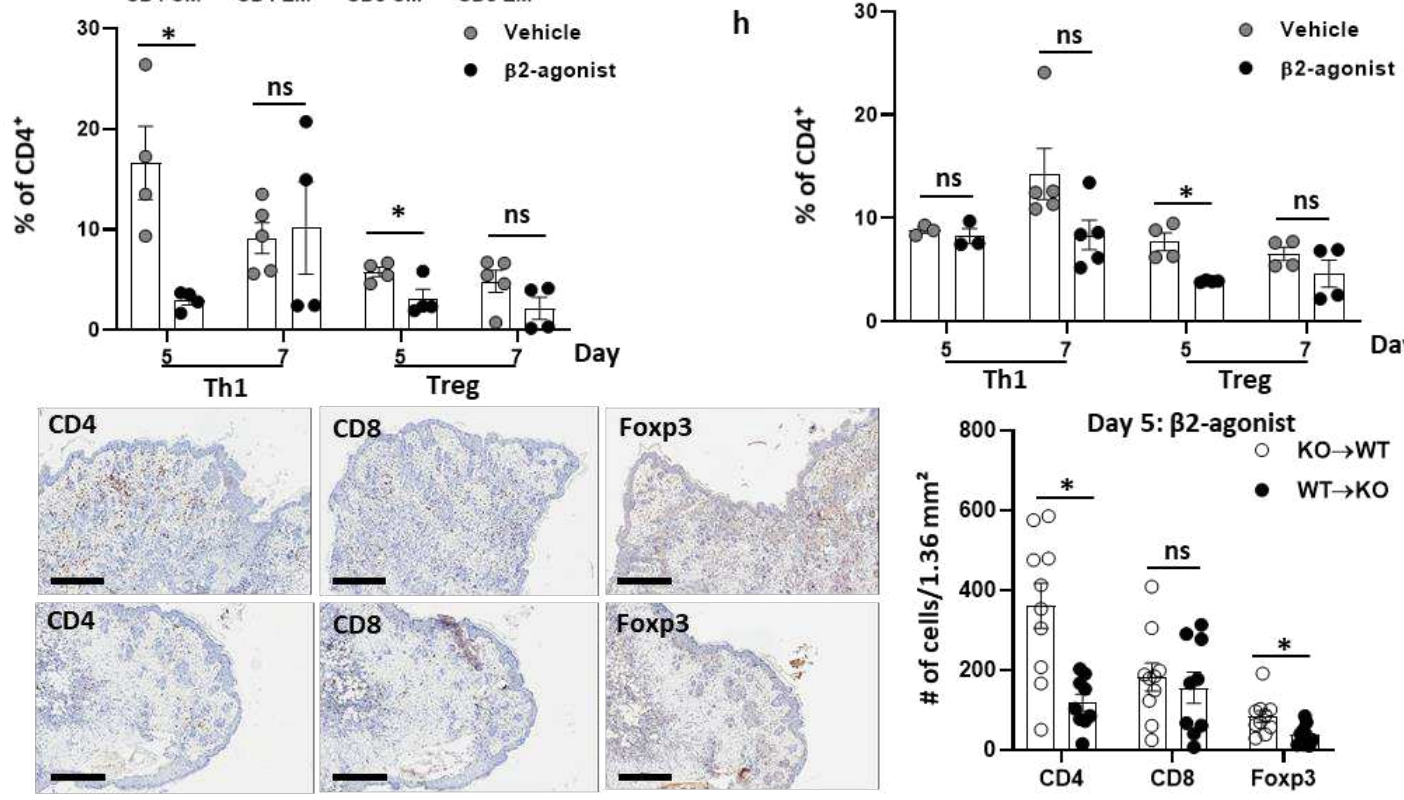

778 Fig. 5: Modulation of $\beta_{2}$-AR signaling in donors is more effective to delay rejection responses than the modulation in recipients. a $\mathrm{BALB} / \mathrm{c} \beta_{2}-\mathrm{AR} \mathrm{KO}$ donors were transplanted to $\mathrm{C} 57 \mathrm{BL} / 6$ recipients with either vehicle or $\beta_{2}$-agonist injections. $\mathbf{b}$, c Compositions of 
$\mathrm{CD}^{+} / \mathrm{CD}^{+} \mathrm{CM} / \mathrm{EM} \mathrm{T}$ cell populations in the spleen 5 and 7 days with either vehicle or $\beta_{2^{-}}$

782

783

784

785

786

787

788

789

790

791

792

793

794

795

796

797 agonist after VCA without tacrolimus in WT recipients receiving BALB/c $\beta_{2}-\mathrm{AR}$ KO grafts. Day $5 ; n=6$, Day $7 ; n \geq 6$, ns; not significant, *; $p<0.05$ by Student's t test, error bar; standard error of the mean. d Th1 and Treg cell populations in $\mathrm{CD}^{+} \mathrm{T}$ cells after vehicle or $\beta_{2}$-agonist treatments in WT recipients receiving BALB/c $\beta_{2}$-AR KO grafts. $n \geq 4$, ns; not significant, *; $p<0.05$ by Student's $t$ test, error bar; standard error of the mean. e BALB/c WT donors were transplanted to $\mathrm{C} 57 \mathrm{BL} / 6 \beta_{2}$-AR KO recipients with either vehicle or $\beta_{2}$-agonist injections. $\mathbf{f}, \mathbf{g}$ Compositions of $\mathrm{CD}^{+} / \mathrm{CD}^{+} \mathrm{CM} / \mathrm{EM} \mathrm{T}$ cell populations in the spleen 5 and 7 days with either vehicle or $\beta_{2}$-agonist after VCA without tacrolimus in $\beta_{2}$-AR KO recipients receiving BALB/c WT grafts. Day $5 ; n \geq 3$, Day $7 ; n \geq 6$, ns; not significant, $* ; p<0.05$ by Student's t test, error bar; standard error of the mean. $\mathbf{h}$ Th1 and Treg cell populations in $\mathrm{CD}^{+} \mathrm{T}$ cells with either vehicle or $\beta_{2}$-agonist treatments in $\beta_{2}$-AR KO recipients receiving BALB/c WT grafts. $n \geq 3$, ns; not significant, *; $p<0.05$ by Student's t test, error bar; standard error of the mean. i Representative figures for IHC with CD4, CD8 and Foxp3 antibodies with $\beta_{2}$-agonist treatment for 5 days in WT recipients bearing AR KO donor's grafts $(\mathrm{KO} \rightarrow \mathrm{WT})$ and AR KO recipients bearing WT donor's grafts (WT $\rightarrow \mathrm{KO})$. Over 9 fields from $n=3$ /group, ns; not significant, *; $p<0.05$ by Student's t test, error bar; standard error of the mean, scale bar; $400 \mu \mathrm{m}$. 
Fig. 6

Day 7: G 1

a

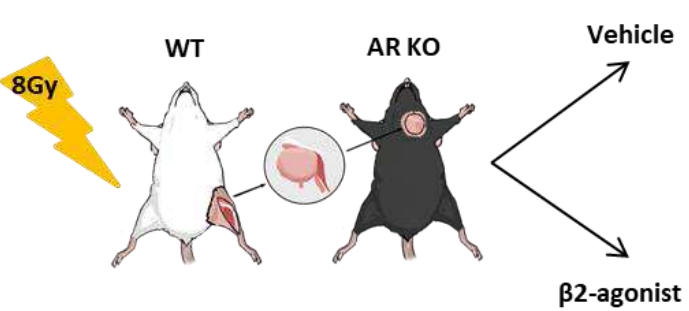

B2-agonist

b

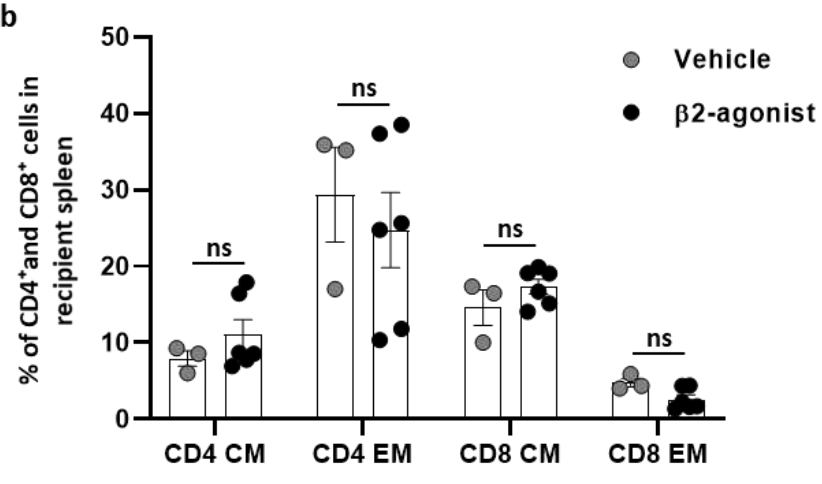

C

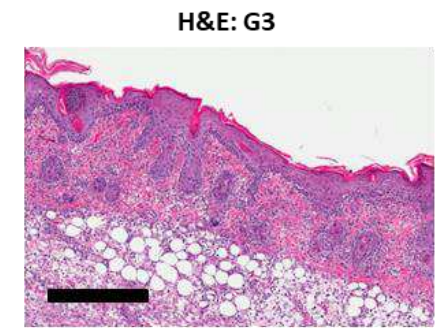

H\&E: G2

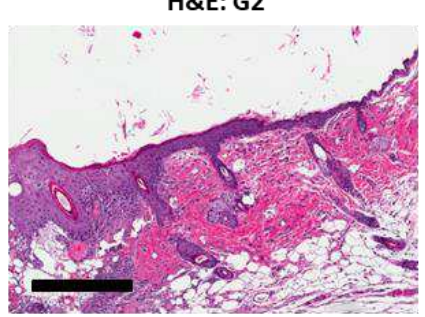

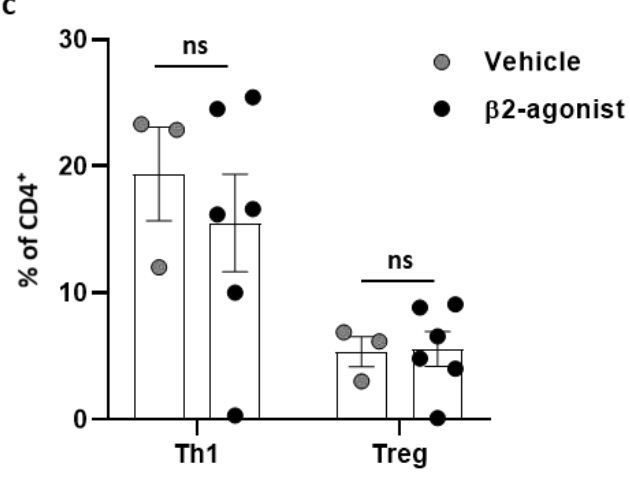

d

CD4

CD8
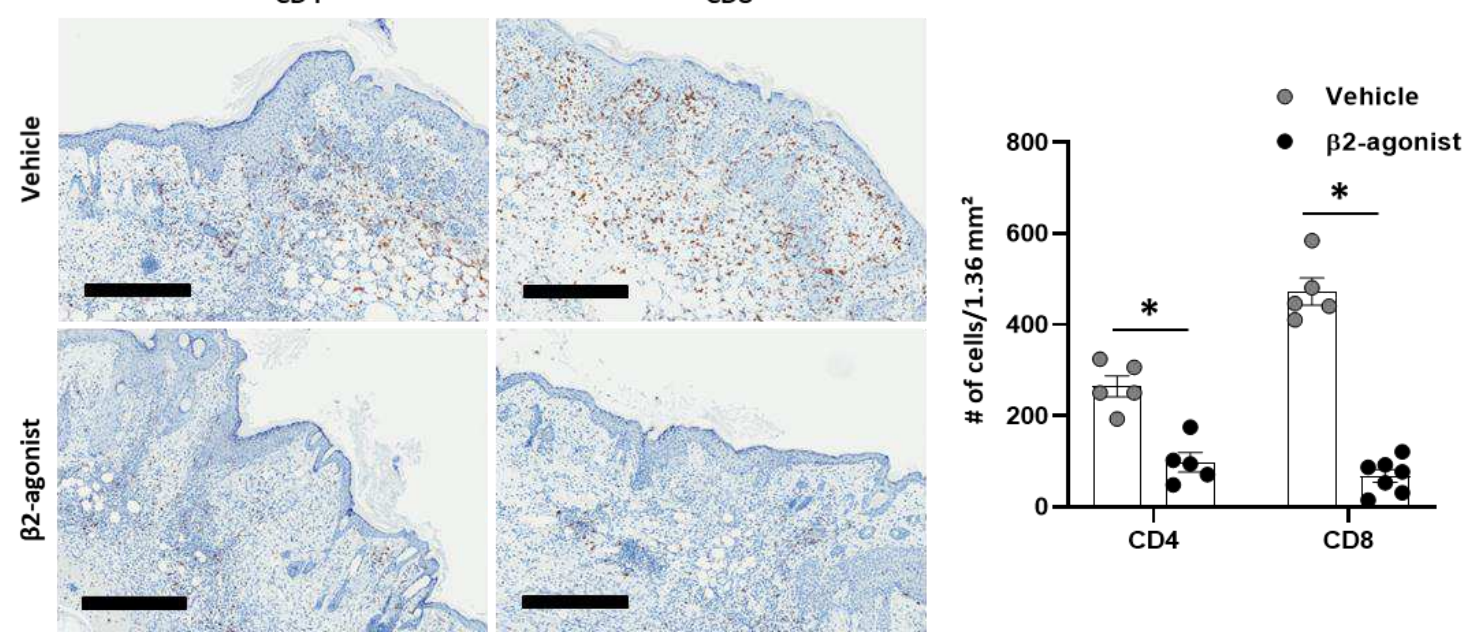

Fig. 6: $\beta_{2}$-AR agonist has effects with donor's stromal cells to inhibit $T$ cell trafficking

into transplanted grafts. a BALB/c WT mice as a donor was exposed to 8 Gy irradiation the

801 day before surgery, the composite graft was transplanted to C57BL/6 $\beta_{2}$-AR KO recipients with either vehicle or $\beta_{2}$-agonist treatments without tacrolimus. $\mathbf{b}, \mathbf{c}$ Compositions of $\mathrm{CD}^{+} / \mathrm{CD}^{+}$ 
$803 \mathrm{CM}$ and EM T cell populations and Th1 and Treg populations. $n \geq 3$, ns; not significant, *; $p<$ 8040.05 by Student's $t$ test, error bar; standard error of the mean. d IHC with CD4/CD8 antibodies, 805 and cells were counted by ImageJ program. Over 5 fields from $n=3$ /group, ns; not significant, $806 * ; p<0.05$ by Student's t test, error bar; standard error of the mean, scale bar; $400 \mu \mathrm{m}$.

Fig. 7

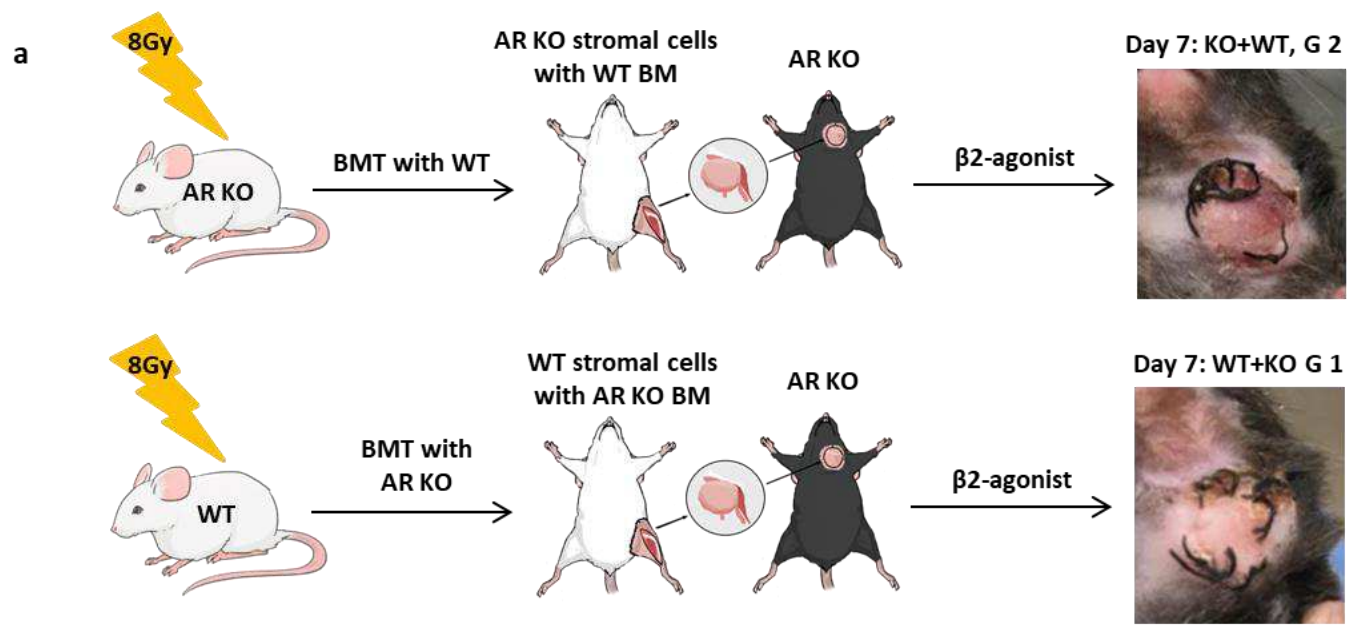

$$
\text { b }
$$
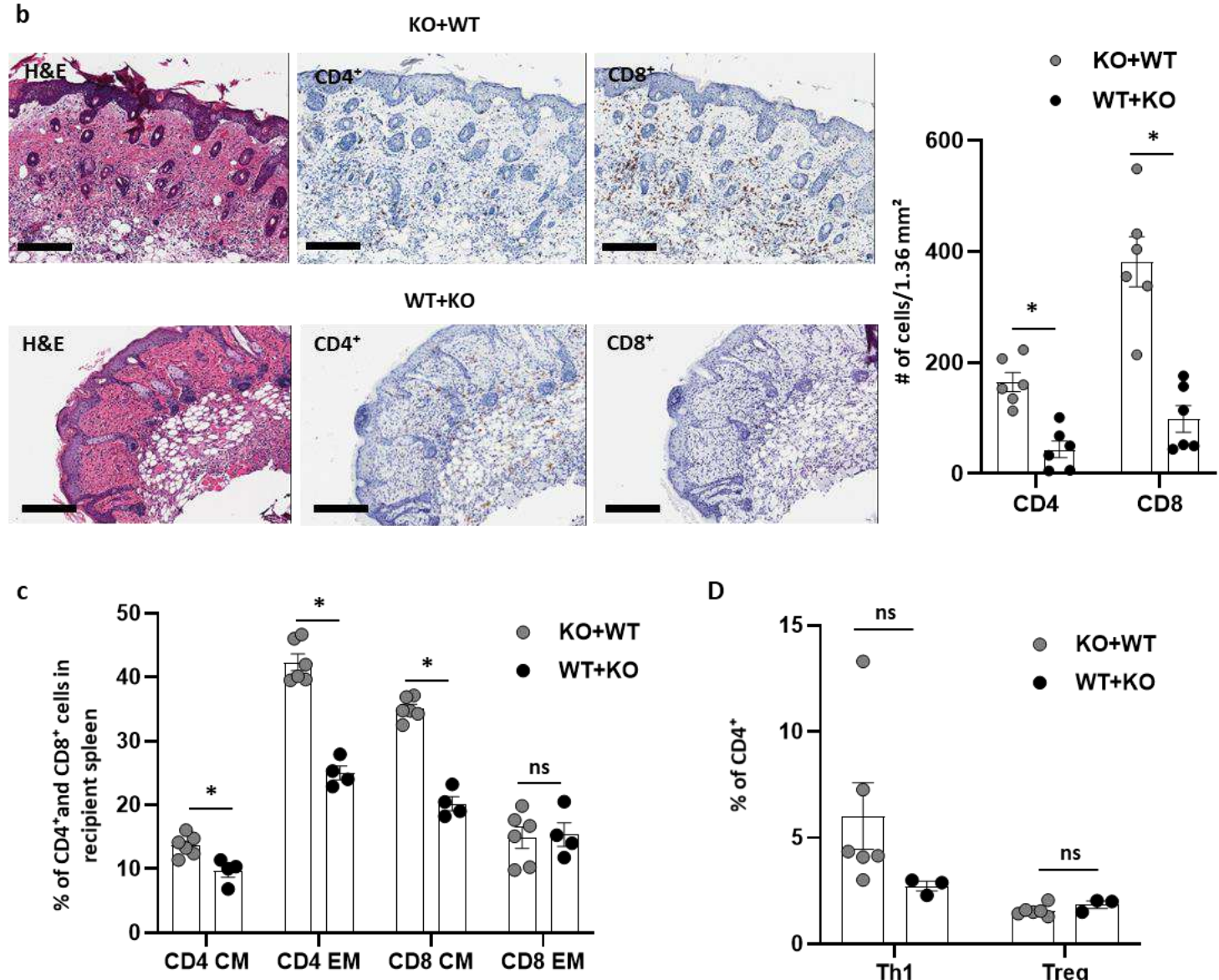

D

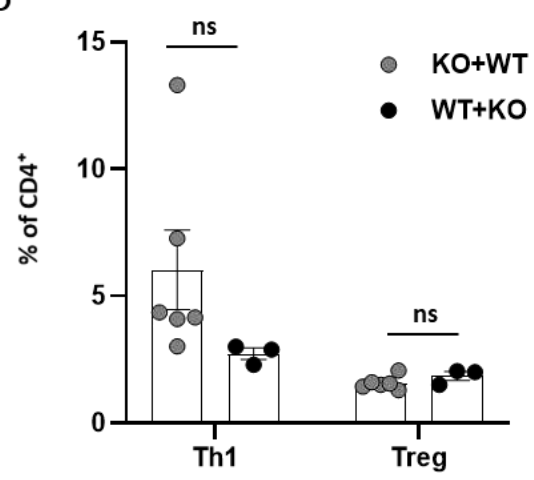



into transplanted grafts. a $\mathrm{BALB} / \mathrm{c} \mathrm{AR} \mathrm{KO}$ and WT donors were exposed to 8 Gy irradiation, and then $\mathrm{BALB} / \mathrm{c}$ WT and $\mathrm{AR} \mathrm{KO} \mathrm{BM}$ were transplanted respectively. After 8-week BM

811 transplantation (BMT), VCA was performed on C57BL/6 AR KO recipients followed by $\beta_{2}$ 812 agonitst treatment for 7 days. b H\&E and IHC with CD4 and CD8 antibodies, 6 fields from $n=$ 8133 /group, $* ; p<0.05$ by Student's t test, error bar; standard error of the mean, scale bar; $200 \mu \mathrm{m}$. $814 \mathbf{c}, \mathbf{d}$ Systemic compositions of $\mathrm{CD}^{+} / \mathrm{CD}^{+} \mathrm{CM} / \mathrm{EM} \mathrm{T}$ cell populations and $\mathrm{Th} 1$ and Treg cell 815 populations in $\mathrm{CD}^{+} \mathrm{T}$ cells 7 days after VCA with $\beta_{2}$-agonist treatment in $\mathrm{C} 57 \mathrm{BL} / 6 \mathrm{AR} \mathrm{KO}$ 816 recipients having a graft from either BALB/c $\beta_{2}-\mathrm{AR}$ KO with WT BMT $(\mathrm{KO}+\mathrm{WT})$ or BALB/c 817 WT with AR KO BMT (WT+KO). $n \geq 3$ ns; not significant, $* ; p<0.05$ by Student's t test, error 818 bar; standard error of the mean. 
Fig. 8
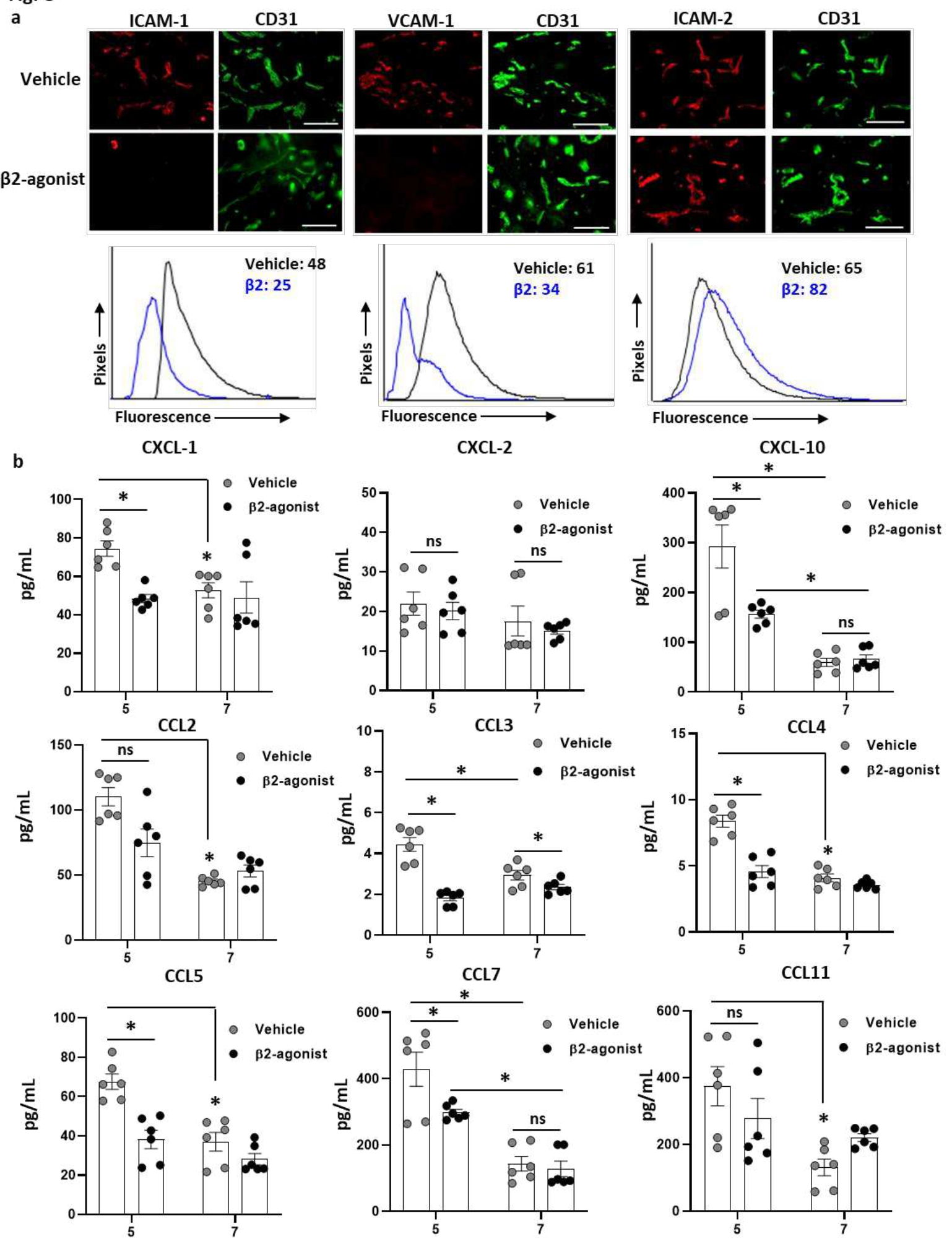

820 Fig. 8: $\beta_{2}$-AR agonist suppresses ICAM-1 and VCAM-1 expression in donor grafts, and 821 significantly decreases CXCL-1, CCL4, and CCL5 in recipients' blood. a 822 Immunofluorescence (IF) and image quantification were performed 5 days after VCA with WT 
823 donors and recipients followed by either vehicle or $\beta_{2}$-agonist injections. ICAM-1, VCAM-1, 824 ICAM-2 and CD31 antibodies were used. Histograms depict quantification of IF intensity of 825 each antibody in all CD31 $1^{+}$vessels; numbers denote Micro-Flow Imaging (MFI). All data are 826 representative of duplicate experiments, $n=3$, scale bar; $100 \mu \mathrm{m}$. b Using Luminex assay, in 827 the setting of WT donors and WT recipients VCA without tacrolimus, various chemokine levels were analyzed 5 and 7 days after transplant. $n=6$; pooled data from duplicate samples, ns; not significant, *; $p<0.05$ by Student's t test, error bar; standard error of the mean.

830

831

832

833

834

835

836

837

838

839

840

841

842

843

844

845

846

847 
Supplementary Fig. 1

a
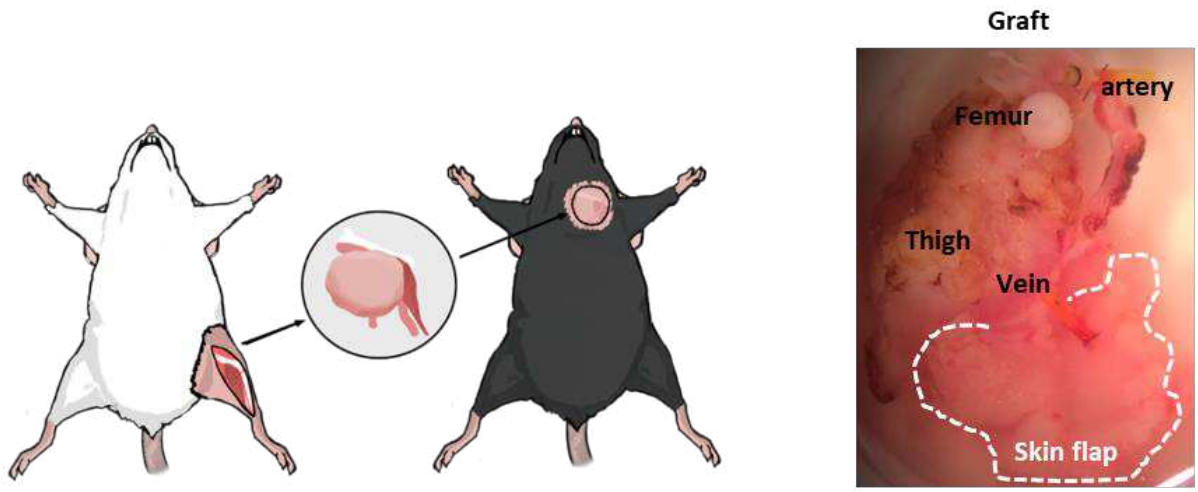

b
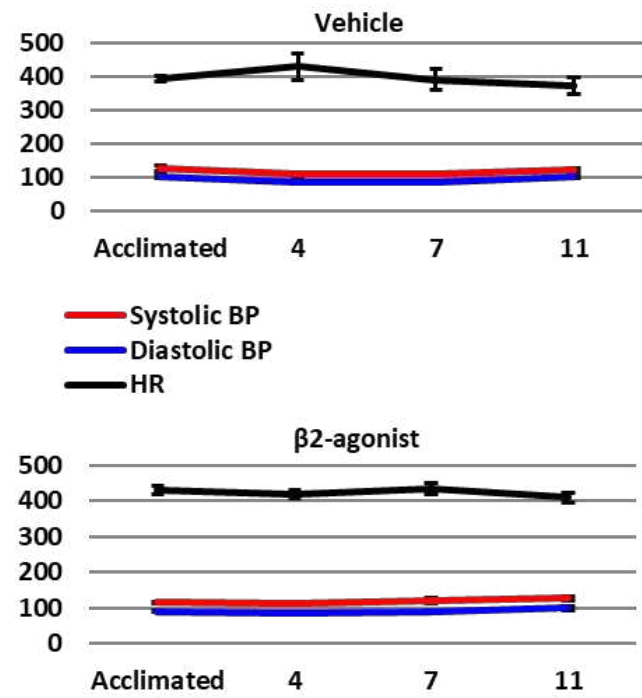

C

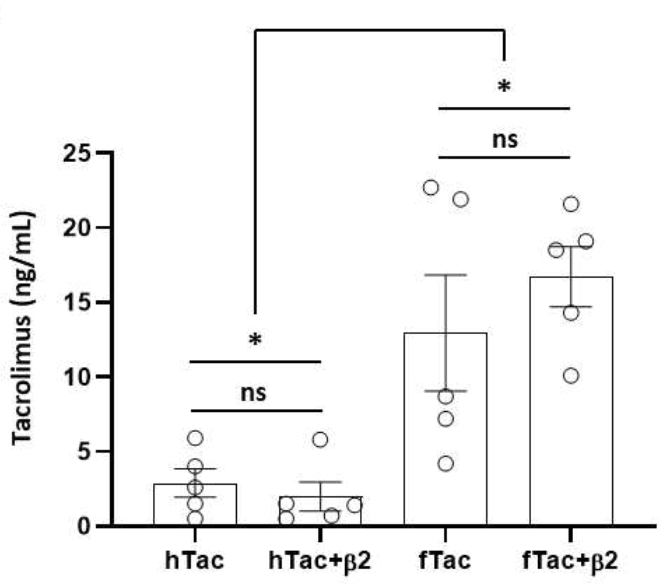

849

Supplementary Fig. 1: A schematic illustration of our VCA model and the safety of a selective $\beta$ 2-adrenergic receptor (AR) agonist drug, terbutaline. a BALB/c and $\mathrm{C} 57 \mathrm{BL} / 6$ strains were used as donors and recipients respectively. En bloc tissue composed of skin, subcutaneous fat, muscle, vessels and femur was transplanted to a recipient's cervical area. $\mathbf{b}$ Systolic and diastolic blood pressure (BP) with heart rates (HR) were measured after everyday injection of with either vehicle (PBS) or $\beta_{2}$-agonist (terbutaline; $2 \mathrm{mg} /$ day). Mice were acclimated to the BP and HR measuring procedures for 10 days before recording data. Representative data between 2 different experiments, $n=5$. c Concentrations of tacrolimus in plasma were analyzed 14 days after subcutaneous injections with either a half dose of tacrolimus (hTac; $2 \mathrm{mg} / \mathrm{kg} / \mathrm{day}$ ) or a full dose of tacrolimus (fTac; $4 \mathrm{mg} / \mathrm{kg} / \mathrm{day}$ ). 
860 Representative data between 2 different experiments, $n=5$, ns; not significant, ${ }^{*} ; p<0.05$ by 861 Student's t test, error bar; standard error of the mean.

862

\section{Supplementary Fig. 2}

a

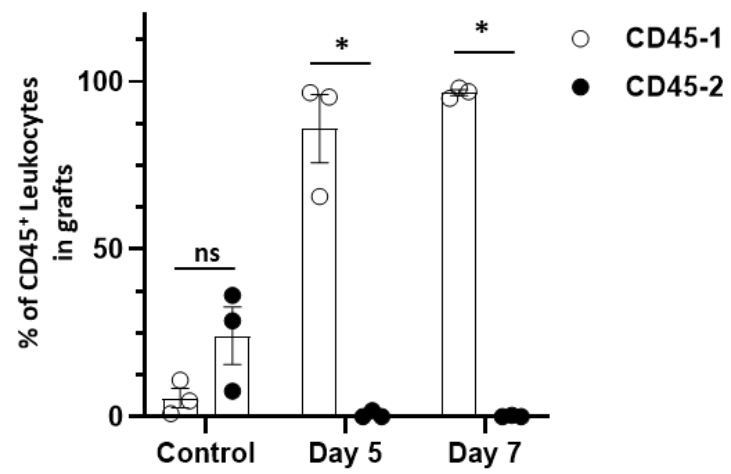

b

863

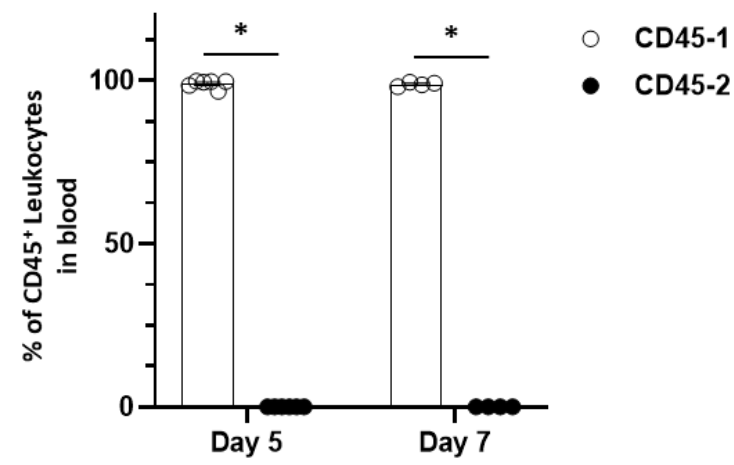

864 Supplementary Fig. 2: The composition of donor's and recipient's leukocytes in donor

865 grafts and recipient blood 5 and 7 days after VCA. a, b Source of infiltrated T cells in 866 transplanted grafts and recipient's blood between recipient (CD45-1) and donor (CD45-2).

867 Control; non-vascularized grafts, $n \geq 3$, ns; not significant, *; $p<0.05$ by Student's t test, error 868 bar; standard error of the mean. 
a

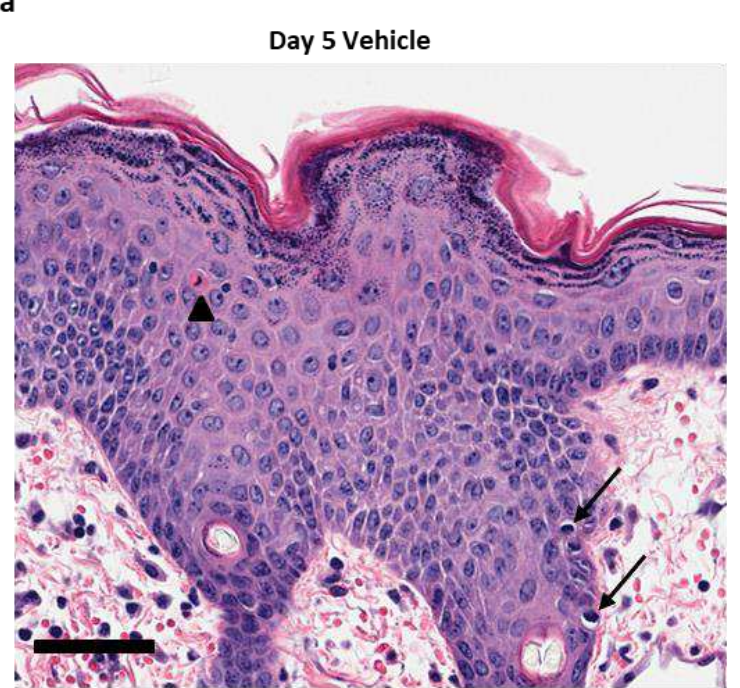

c

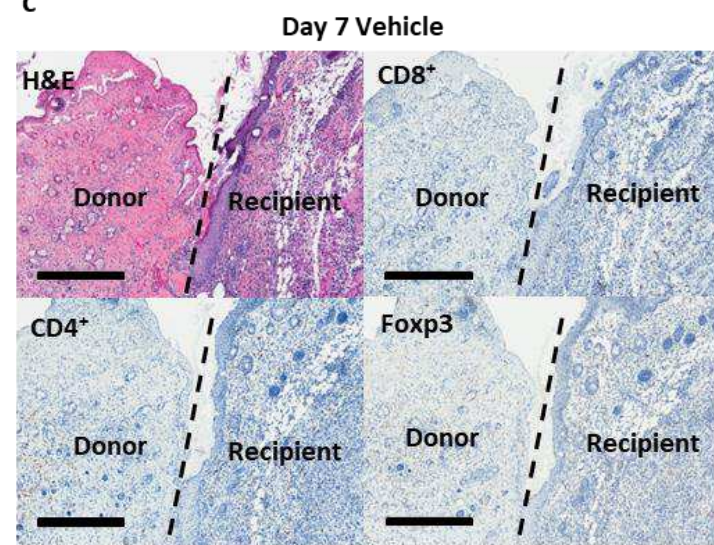

b

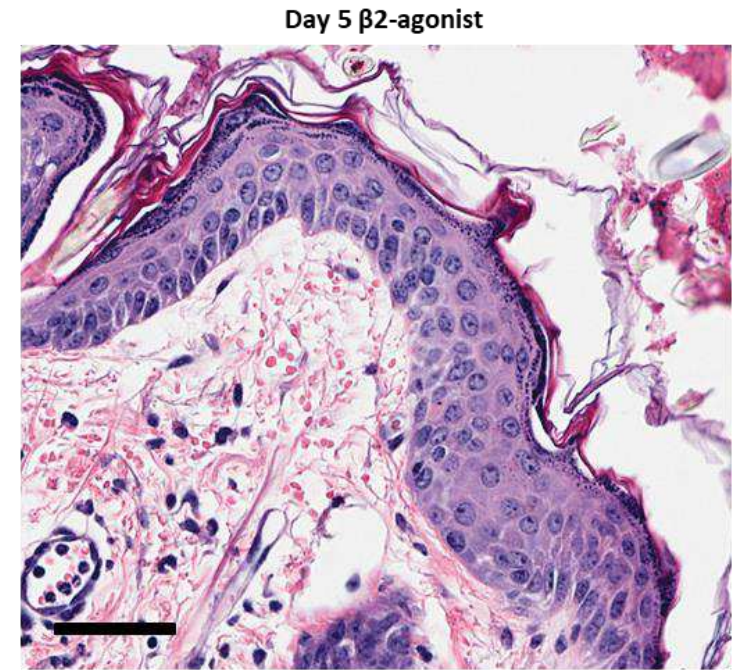

d

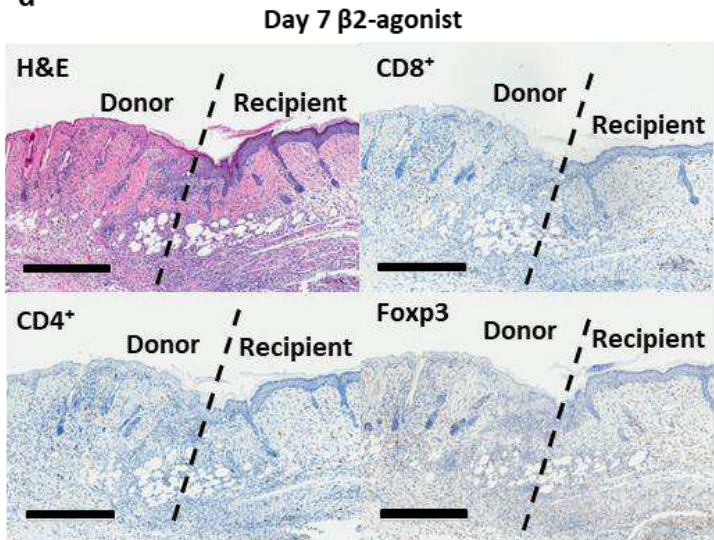

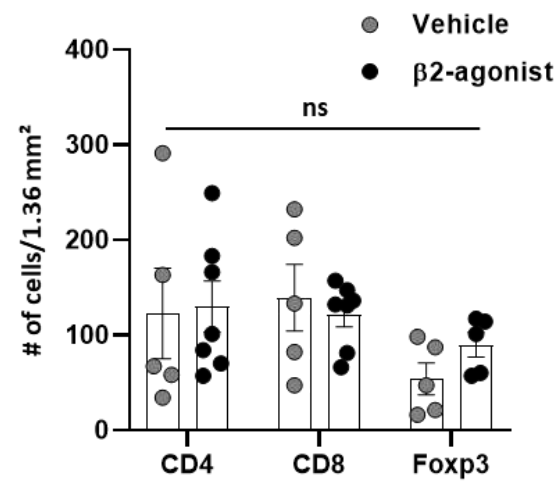

f

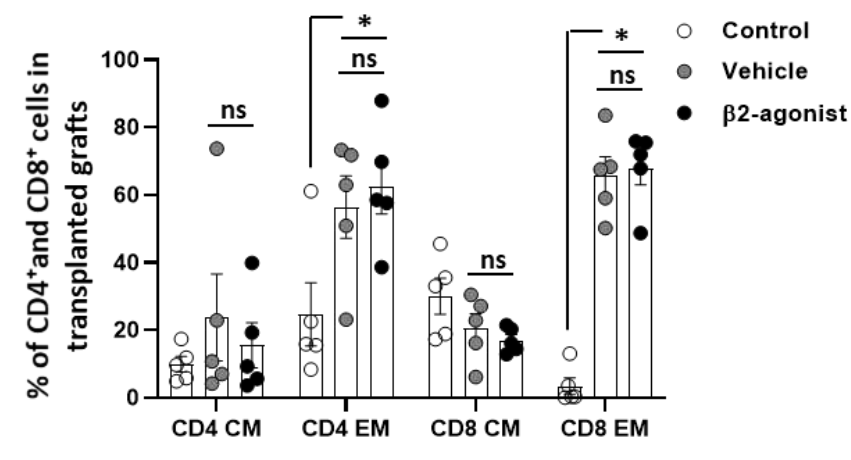

871 Supplementary Fig. 3: Pathologic findings 5 and 7 days after VCA with either vehicle or

$872 \boldsymbol{\beta}_{2}$-agonist injections. a, b Representative H\&E images revealed epithelial dyskeratosis

873 (arrowhead) and apoptosis (arrow) in the vehicle injected group (a; rejection grade 3) not in

874 the $\beta_{2}$-agonist injected group (b; rejection grade 2) 5 days after VCA, scale bar: $50 \mu \mathrm{m}$. $\mathbf{c}, \mathbf{d}$ 
Representative figures for $\mathrm{H} \& \mathrm{E}$ and IHC with CD8, CD4, and Foxp3 antibodies either with vehicle or $\beta_{2}$-agonist treatment for 7 days. e Numbers of CD4, CD8, and Foxp3 positive cells in grafts 7 days after VCA. 9 fields from 3 grafts per group, ns; not significant, error bar; standard error of the mean. $\mathbf{f}$ Compositions of $\mathrm{CD} 4^{+} / \mathrm{CD} 8^{+} \mathrm{CM}$ and $\mathrm{EM} \mathrm{T}$ cell populations in transplanted grafts 7 days after VCA. Control; non-vascularized grafts, $n=5$, ns; not significant, *; $p<0.05$ by Student's t test, error bar; standard error of the mean, scale bar; $400 \mu \mathrm{m}$.

\section{Supplementary Fig. 4}

a

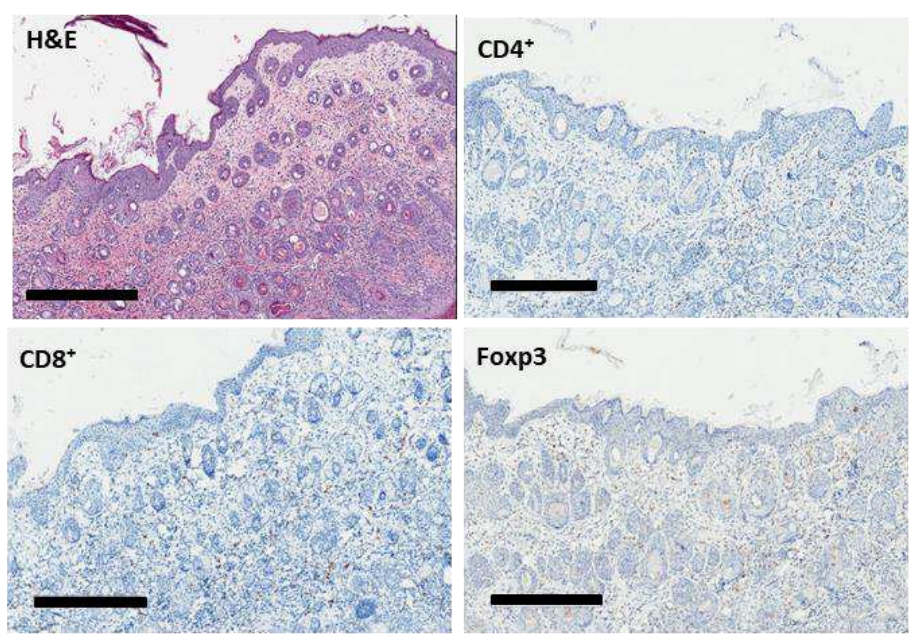

b

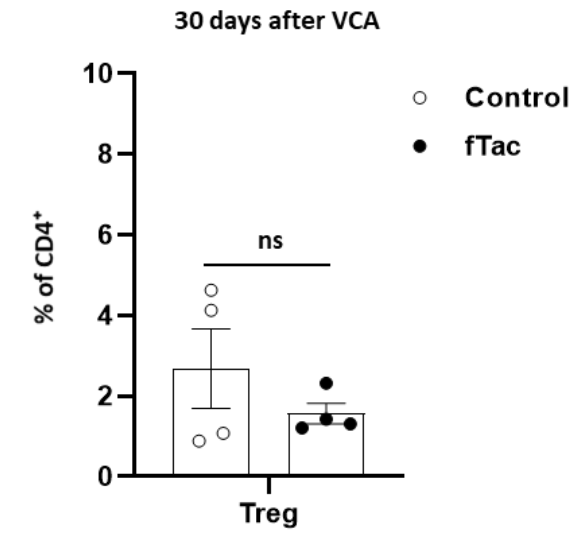

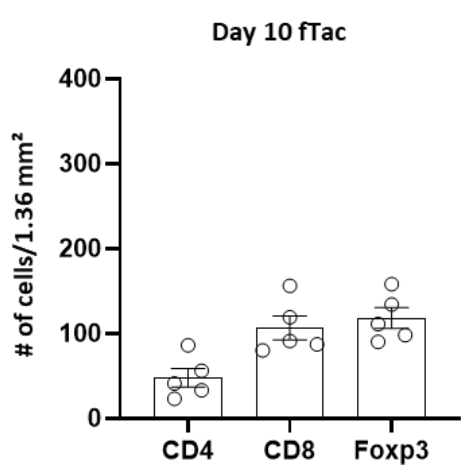

882

Supplementary Fig. 4: Numbers of Foxp3 $3^{+}$cell in transplanted grafts and the composition of Treg $\left(\mathrm{CD4}^{+} \mathrm{CD25}^{+} \mathrm{Foxp3}^{+}\right)$population with fTac injections after VCA. a Representative figure for $\mathrm{H} \& \mathrm{E}$ and IHC with numbers of CD4, CD8 and Foxp3 cells 10 days after VCA. 5 
888 VCA, $n=4$, ns; not significant, error bar; standard error of the mean.

\section{Supplementary Fig. 5}

a

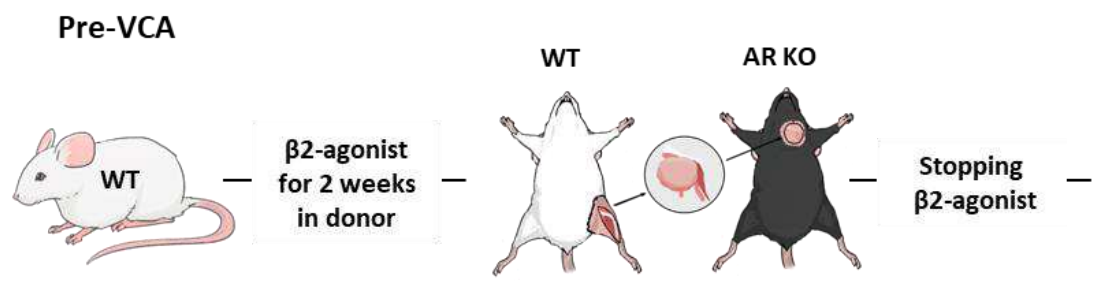

Post-VCA

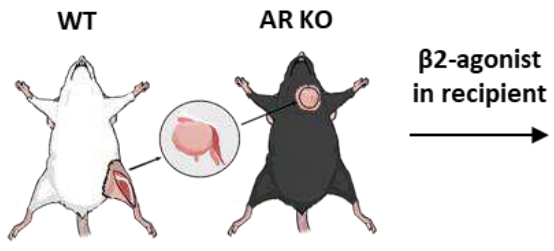

b

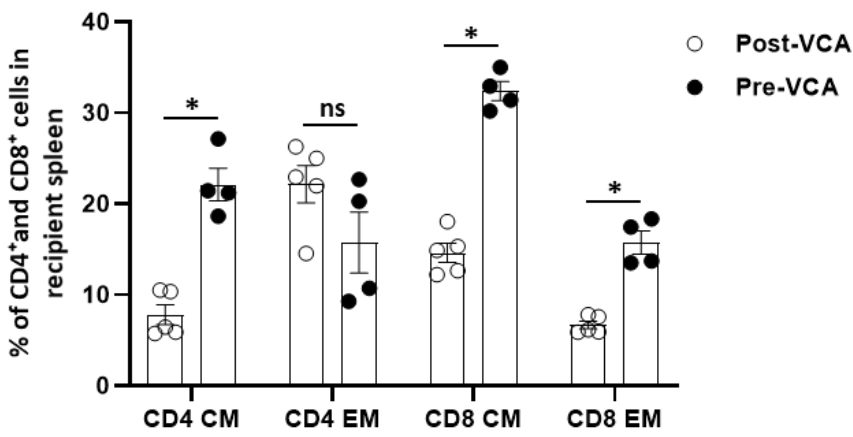

d

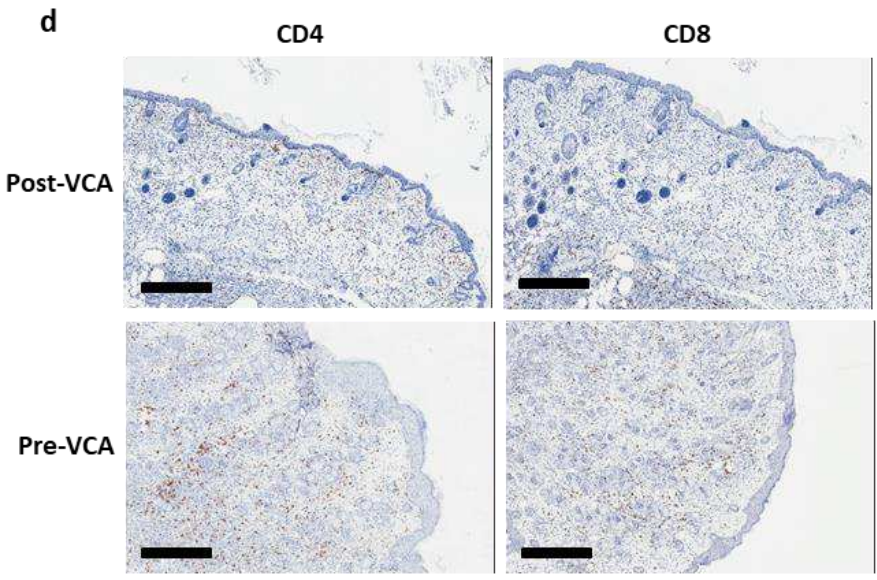

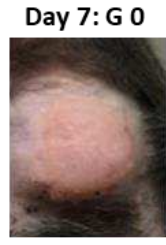

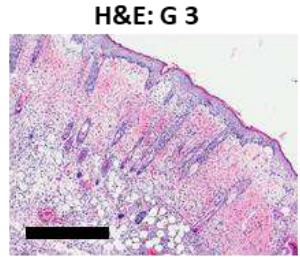

Day 7: G 1
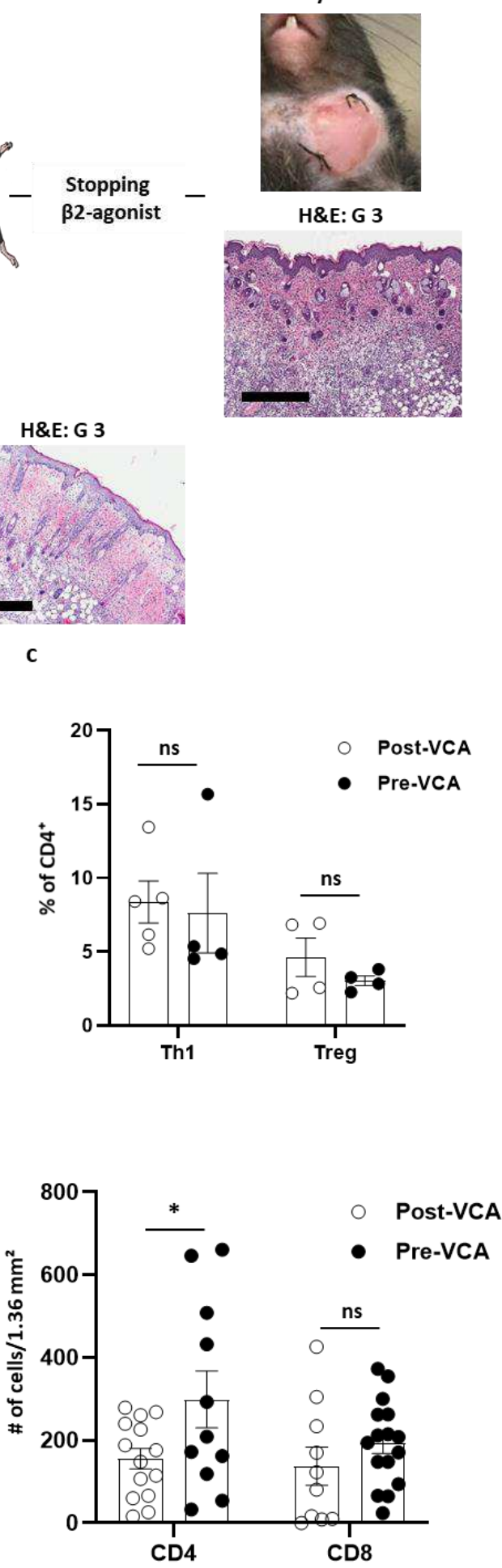

the surgery in C57BL/6 AR KO recipients. Representative figures, scale bar; $400 \mu \mathrm{m}$. b Systemic compositions of $\mathrm{CD} 4^{+} / \mathrm{CD} 8^{+} \mathrm{CM}$ and EM T cell populations 7 days after VCA. $\mathbf{c}$ Th1 and Treg cell populations in $\mathrm{CD}^{+}{ }^{\mathrm{T}}$ cells. $n \geq 4$ mice ${ }^{*} ; p<0.05$ by Student's t test, ns; not significant, error bar; standard error of the mean. $\mathbf{d}$ Numbers of CD4 and CD8 positive cells in grafts 7 days after VCA. Over 10 fields from 3 mice/group *; $p<0.05$ by Student's t test, ns; not significant, error bar; standard error of the mean, scale bar; $400 \mu \mathrm{m}$. Data with empty circles (Post-VCA); historical data.

900

\begin{tabular}{|c|c|c|}
\hline Grade & Visual assessment & Histologic assessment \\
\hline $0:$ No rejection & $\begin{array}{l}\text { Normal epidermal and dermal } \\
\text { appearance without evidence of } \\
\text { rejection. }\end{array}$ & No or rare inflammatory infiltrates. \\
\hline $\begin{array}{l}\text { 1: Indeterminate/ } \\
\text { supposed rejection }\end{array}$ & $\begin{array}{l}\text { Very early visual signs of rejection. Focal } \\
(<25 \%) \text { inconspicuous changes in the } \\
\text { skin color. }\end{array}$ & $\begin{array}{l}\text { Mild. Mild perivascular infiltration. No } \\
\text { involvement of the overlying epidermis. }\end{array}$ \\
\hline 2: Mild rejection & $\begin{array}{l}\text { Clear visual signs of rejection. Diffuse } \\
(25 \%-50 \%) \text { clear changes in color and } \\
\text { texture of skin. }\end{array}$ & $\begin{array}{l}\text { Moderate. Moderate-to-severe perivascular } \\
\text { inflammation with or without mild epidermal } \\
\text { and/or adnexal involvement (limited to } \\
\text { spongiosis and exocytosis). No epidermal } \\
\text { dyskeratosis or apoptosis. }\end{array}$ \\
\hline $\begin{array}{l}\text { 3: Moderate } \\
\text { rejection }\end{array}$ & $\begin{array}{l}\text { Extensive (>50\%) and advances } \\
\text { alteration of skin quality such as } \\
\text { desquamation, scabs, skin crusts. }\end{array}$ & $\begin{array}{l}\text { Severe. Dense inflammation and epidermal } \\
\text { involvement with epithelial apoptosis, } \\
\text { dyskeratosis and/or keratinolysis. }\end{array}$ \\
\hline 4: Severe rejection & $\begin{array}{l}\text { Destruction of epidermis with intact } \\
\text { dermis or complete destruction of the } \\
\text { skin. }\end{array}$ & $\begin{array}{l}\text { Necrotizing acute rejection. Frank necrosis of } \\
\text { epidermis or other skin structures. }\end{array}$ \\
\hline
\end{tabular}

